\title{
Wind driven upwelling and surface nutrient delivery in a semi-enclosed coastal sea
}

\author{
Ben Moore-Maley ${ }^{1}$ and Susan E. Allen ${ }^{1}$ \\ ${ }^{1}$ Department of Earth, Ocean and Atmospheric Sciences, University of British Columbia, 2207 Main Mall, Vancouver, BC \\ V6T 1Z4, Canada
}

Correspondence: Ben Moore-Maley (bmoorema@eoas.ubc.ca)

\begin{abstract}
.
Wind driven upwelling is an important control on surface nutrients and water properties in stratified lakes and seas. In this study, a high resolution biophysical coupled model is used to investigate upwelling in the Strait of Georgia. The model is forced with surface winds from a high resolution atmospheric forecast and reproduces extensive observations of water level, temperature, salinity, nutrients and chlorophyll with competitive skill relative to similar models of the study region. Five years of hourly surface nitrate and temperature are analyzed in order to characterize the dominant upwelling patterns of the basin. An along-axis wind climatology steered by mountainous topography produces episodic upwelling along the western shore during the spring and fall southeasterlies and along the eastern shore during the summer northwesterlies, as indicated by positive nitrate anomalies. Principal component analysis reveals that these cross-axis upwelling patterns account for nearly one-third of the surface nitrate variance during the productive season. By contrast, nearly half of the surface temperature variance over the same period is dominated by a single mixing-heating pattern. The principal components associated with these patterns correlate with wind stress in a manner consistent with these physical interpretations. The cross-axis upwelling response to wind is similar to other dynamically wide basins where the baroclinic Rossby deformation radius is smaller than the basin width. However, the nitrate anomaly during upwelling along the eastern shore is stronger in the northern basin, which may be indicative of an along-axis pycnocline tilt or an effect of the background along-axis stratification gradient due to the Fraser River. Our findings highlight an important spatio-temporal consideration for future ecosystem monitoring.
\end{abstract}

\section{Introduction}

Wind driven upwelling is ubiquitous in the coastal ocean (Kämpf and Chapman, 2016) and in large, enclosed seas (e.g., Silvestrova et al., 2019; Lehmann et al., 2012; Plattner et al., 2006). This process provides an important pathway for vertical nutrient transport into the euphotic zone (Messié and Chavez, 2015) but can also be a source of environmental stress by introducing large amplitude fluctuations of temperature, dissolved oxygen, $\mathrm{pCO}_{2}, \mathrm{pH}$ and aragonite saturation state near the coast (Chan et al., 2017). Consequently, upwelling variability can dramatically alter seasonal biological community structure across a wide trophic range (Barth et al., 2007), and persistent upwelling is often a defining feature of ecosystems such as along Pacific and Atlantic eastern boundaries (Chavez and Messié, 2009). Additionally, upwelling has been observed to influence 
https://doi.org/10.5194/os-2021-21

Preprint. Discussion started: 1 April 2021

phytoplankton distributions in large lakes (Mziray et al., 2018; Bouffard et al., 2018) and can mitigate or exacerbate problems associated with anthropogenic eutrophication in urbanized regions such as cyanobacteria blooms in the Baltic Sea (Wasmund et al., 2012) and hypoxia in Lake Erie (Rowe et al., 2019).

In enclosed basins, coastal upwelling describes the pycnocline displacements that result from wind driven horizontal divergence near a coastline and any oscillations that follow. However, the structure of these pycnocline displacements strongly depends on basin scale. This scale can be described by the width of the basin relative to the internal Rossby deformation radius $L_{\mathrm{R}}$, which is defined in a two-layer approximation as

$$
L_{\mathrm{R}}=\frac{1}{f} \sqrt{\frac{g \Delta \rho}{\rho_{0}} \frac{h_{1} h_{2}}{h_{1}+h_{2}}}
$$

where $f$ is the Coriolis parameter, $g$ is the gravitational acceleration, $\Delta \rho$ is the density difference across the pycnocline, $\rho_{0}$ is the background density and $h_{1}$ and $h_{2}$ are the respective upper and lower layer thicknesses. Given a sustained, along-axis wind impulse, if the basin is much wider than $L_{\mathrm{R}}$ then Ekman fluxes freely develop and the pycnocline displacement is cross-axis. If the basin is narrower than $L_{\mathrm{R}}$ then Ekman fluxes are rapidly opposed by cross-axis pressure gradients and cannot fully form, forcing the surface layer transport to flow along-axis which sets up an end-to-end pycnocline tilt (Csanady, 1982). Upwelling studies across a range of dynamic scales support this theory. Cross-axis upwelling is primarily observed in large seas like the Baltic Sea sub-basins (Bednorz et al., 2019; Delpeche-Ellmann et al., 2017; Zhurbas et al., 2008) and the North American Great Lakes (Plattner et al., 2006; Csanady, 1977) while along-axis upwelling is primarily observed in narrow basins like the glacial reservoirs of British Columbia (Imam et al., 2013; Laval et al., 2008). The along-axis pycnocline setup in lakes progresses as a set of internal seiche modes excited by the initial wind impulse (Stevens and Lawrence, 1997; Spigel and Imberger, 1980). If the lake is wide enough, these seiches can be amphidromic to the point of resembling Kelvin waves, even if the initial pycnocline setup is along-axis (Roberts et al., 2021; Bouffard and Lemmin, 2013; Valerio et al., 2012).

Upwelling can be influenced by several factors in addition to dynamic scale. For example, local wind variability may produce secondary upwelling features superimposed on the basin scale setup. Wind stress curl has been implicated in observations of cyclonic circulation cells and open water upwelling in large lakes such as Lake Baikal (Troitskaya et al., 2015) and Lake Michigan (Schwab and Beletsky, 2003), while wind is aligned primarily along-axis in narrow mountain lakes due to topographic steering (e.g., Quesnel Lake, Thompson et al., 2020). This along-axis tendency is particular strong in high latitude fjords where katabatic winds are common (Lundesgaard et al., 2019; Spall et al., 2017). Topographic features such as thalweg geometry in narrow lakes (Shintani et al., 2010) and offshore bottom slope in wide basins (Delpeche-Ellmann et al., 2018; Choboter et al., 2011; Lentz and Chapman, 2004) can affect the strength of upwelling at the coast. In wide basins and along continental margins, the along-shore current that forms during cross-shore upwelling can separate from the coast over shallow banks to conserve potential vorticity, as observed in the Baltic Sea (Gurova et al., 2013) and along the central Oregon coast (Castelao and Barth, 2005). If spatial salinity gradients are strong, near river plumes for example, baroclinic pressure gradients can weaken or amplify the wind driven pycnocline tilt ( $\mathrm{Li}$ and $\mathrm{Li}, 2012)$. Finally, bottom roughness and turbulent bottlenecks can result in complete damping of the internal wave response in narrow lakes (e.g., Nechako Reservoir, Imam et al., 2013). 
In this study, we explore wind driven upwelling in the Salish Sea estuarine fjord network on the Canadian west coast. We focus our analysis on the Strait of Georgia (SoG), which is the largest and most protected basin in the Salish Sea. The SoG is a globally significant ecosystem that provides critical habitat to several keystone fisheries including the iconic Fraser River sockeye salmon (Thomson et al., 2012) and the endangered Southern Resident Killer Whale (Wasser et al., 2017). The SoG also contains over half of the shellfish aquaculture leases in Pacific Canada, most of which are concentrated in just two sheltered regions. Salinity gradients in the SoG are large due to significant runoff from surrounding mountainous watersheds and deep estuarine inflows from the Pacific Ocean. These oceanic inflows combined with local remineralization of organic matter make the deep SoG nutrient and carbon rich (Sutton et al., 2013; Ianson et al., 2016), while the surface is nutrient and carbon poor due to strong seasonal primary productivity.

The importance of wind in controlling this productivity is well-established. During the transition from winter to spring, the expansion of the North Pacific High suppresses winter storm activity in the region (Bakri and Jackson, 2019). Calm winds and clear skies provide light and stratification for a spring phytoplankton bloom to occur (Collins et al., 2009). Surface nutrients are rapidly depleted and remain low throughout the summer. Further wind activity throughout this period introduces additional nutrients to the surface allowing smaller blooms to occur (Yin et al., 1997). Additionally, large surface $\mathrm{pCO}_{2}$ fluctuations have been observed to occur near sensitive shellfish aquaculture zones in the northern SoG following northerly wind impulses (Evans et al., 2018). Poor spatial and temporal resolution in most existing studies has prevented a more detailed analysis of surface nutrient delivery in the SoG, and so these nutrient and $\mathrm{pCO}_{2}$ pulses are generally attributed to vertical wind mixing (e.g., Yin et al., 1997). However, cross-axis asymmetry of satellite sea surface temperature (Evans et al., 2018) and modelled surface nitrate (Olson et al., 2020) identified during more recent along-axis wind events in the northern SoG suggests that upwelling is a significant driver of these nutrient pulses.

Here we analyze 5 years of hourly, high resolution surface nitrate and temperature results from a biophysical coupled model of the Salish Sea along with hourly, high resolution surface wind forcing fields from an operational Canadian weather model in order to better characterize the mechanism of wind driven surface nutrient delivery in the SoG. Using principal component analysis, we identify persistent spatial patterns in surface nitrate and temperature anomalies that correlate with the wind forcing record. We then characterize the physical mechanisms that determine each spatial pattern according to the sign of the correlation to wind stress. This study is the first to explicitly identify wind driven upwelling in the SoG, and the results introduce a fundamental nutrient delivery mechanism that is currently unexplored in SoG ecosystem studies. This study also provides a further basis for interpreting surface temperature and $\mathrm{pCO}_{2}$ fluctuations like those observed in the northern SoG (Evans et al., 2018). Finally, this study corroborates the well-established cross-axis patterns of upwelling in large basins such as the Baltic Sea and North American Great Lakes but for a strongly stratified estuarine fjord system. 


\section{Methods}

\subsection{Study area}

The SoG is approximately $200 \mathrm{~km}$ long, $40 \mathrm{~km}$ wide and $400 \mathrm{~m}$ deep along the thalweg (Fig. 1). The primary connection to the Pacific Ocean is located at the southern end of the basin through Haro and Rosario Straits while a secondary connection to the north through Johnstone Strait accounts for a small fraction of the oceanic exchange (Pawlowicz et al., 2007). The exchange between the SoG and the Pacific Ocean is forced by estuarine circulation fed by local watersheds as well as the approximately $220,000 \mathrm{~km}^{2}$ Fraser River drainage basin. This circulation cell is significantly modulated by mixing due to 2-4 m amplitude mixed diurnal-semidiurnal tides (Foreman et al., 1995), primarily over the respective 100 and $50 \mathrm{~m}$ sill depths in the narrow Haro and Johnstone Straits. This tidal modulation recycles outgoing brackish water back into the intermediate and deep SoG the incoming water through Haro Strait, for example, is composed of approximately 60\% outgoing surface water (Pawlowicz et al., 2019). However, annual flushing maintains high salinity in the deep basin (Masson, 2002) and strong vertical salinity gradients during peak runoff.

Oceanic inflows driven by estuarine circulation are the primary sources of nitrate (Mackas and Harrison, 1997) and dissolved inorganic carbon (Ianson et al., 2016) to the SoG. Additionally, these tracers are constantly recirculated into the SoG via tidal mixing. This process proceeds differently at opposite ends of the basin. At the southern end, the recirculated tidal jet from Haro Strait readily subducts into the intermediate layer as a gravity current (Thomson et al., 2020) and transiently reaches the surface through slow upward mixing followed by entrainment and frontal dynamics surrounding the Fraser River plume (Parsons et al., 1981). At the northern end of the basin, the recirculated tidal jet is injected directly into the surface layer from Johnstone Strait at near-neutral buoyancy and flows south along the western side of the basin while gradually sinking toward Baynes Sound (Olson et al., 2020).

Away from these tidal nutrient sources, stratification and river plume dynamics determine the overall chlorophyll biomass distribution in the SoG. Stratification reaches a maximum in the Fraser plume at the southern end of the basin and gradually decreases toward the north (Masson and Peña, 2009). During the productive season, the chlorophyll distribution reflects the stratification gradient in two important ways. While surface chlorophyll generally decreases from south to north following the stratification gradient (Suchy et al., 2019; Masson and Peña, 2009), the chlorophyll depth range increases from south to north (Masson and Peña, 2009) such that total integrated chlorophyll shows no consistent bias toward any one region (Pawlowicz et al., 2020). An exception to this pattern is found directly within the Fraser plume where phytoplankton are restricted to a thin surface layer (Halverson and Pawlowicz, 2013) and river turbidity reduces light availability (Moore-Maley et al., 2016), although the plume boundary can produce elevated chlorophyll due to frontal dynamics (Parsons et al., 1981). A subtle, crossaxis stratification gradient also arises due the disproportionate summer runoff from the glacially fed watersheds along the eastern side of the basin. This gradient is consistent with modelled (Peña et al., 2016) and observed (Suchy et al., 2019) crossaxis chlorophyll gradients and has been implicated as a driver of observed flagellate community clusters along the northeastern coastline (Haigh and Taylor, 1991). 
https://doi.org/10.5194/os-2021-21

Preprint. Discussion started: 1 April 2021

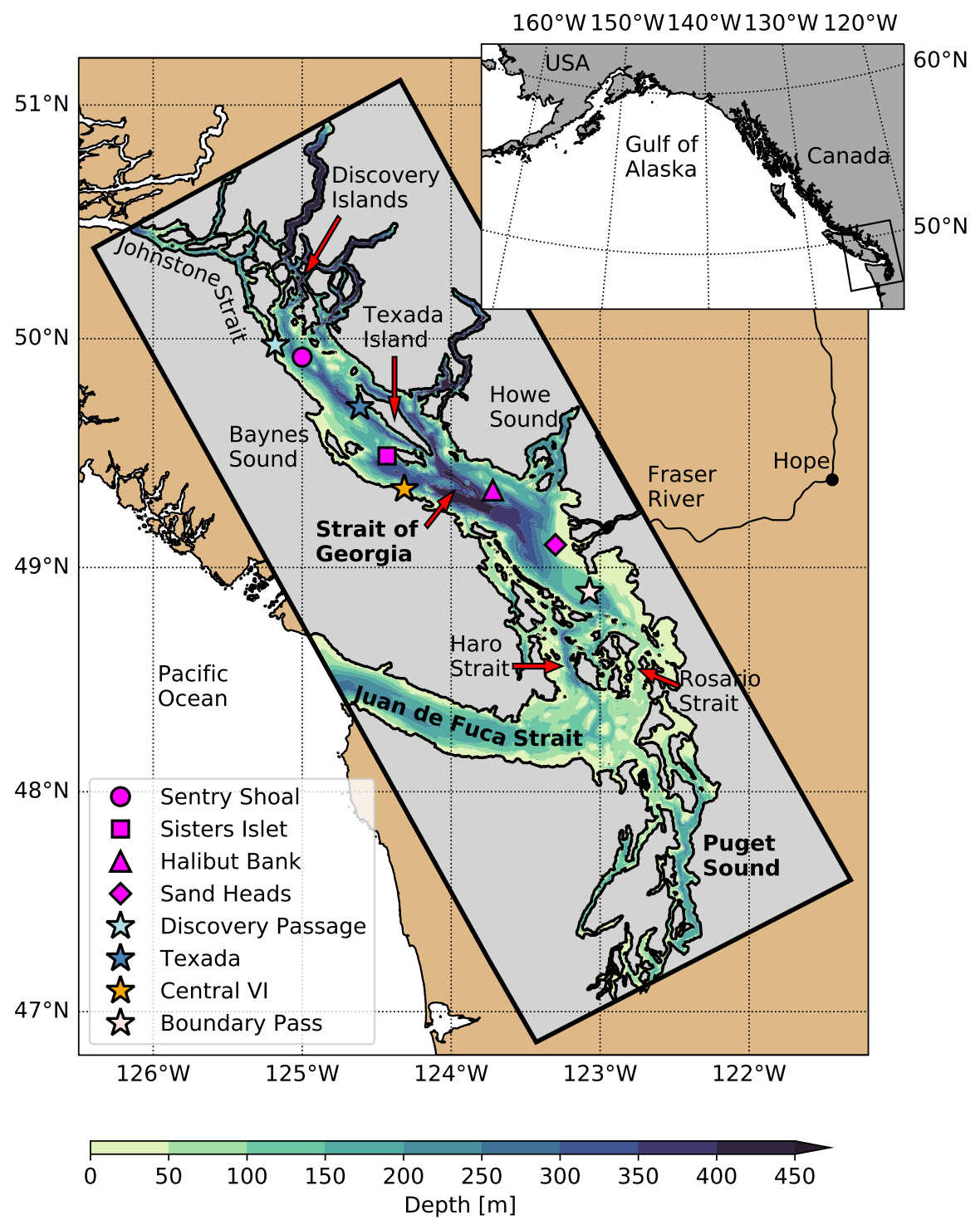

Figure 1. Map of the Salish Sea study region with the SalishSeaCast model domain overlaid as a gray box and contoured bathymetry. Relevant geographic features, meteorological observing platforms (magenta symbols) and modelled surface nitrate locations (stars) referenced in this study are also shown. The Texada and Central Vancouver Island (VI) locations are positioned along the respective eastern and western shores of the Strait of Georgia where upwelling dominates, while the Discovery Passage and Boundary Pass locations are positioned at the northern and southern ends of the basin where tidal mixing dominates. Coastline data were obtained from the GSHHS database (Wessel and Smith, 1996).

Wind and cloud fraction are important drivers of seasonal chlorophyll cycles. As mentioned earlier, wind relaxation and weakening cloud cover facilitate the spring diatom bloom (Collins et al., 2009) and subsequent wind activity enhances chloro- 
https://doi.org/10.5194/os-2021-21

Preprint. Discussion started: 1 April 2021

phyll by bringing nutrients to the surface (Yin et al., 1997). Local weather is determined by the synoptic scale meteorology of the northeast Pacific Ocean. Winter storm activity is dominated by extra-tropical cyclones that form along the polar jet stream and produce primarily southeast winds and significant precipitation when they make landfall along the outer coast (Read, 2015; Thompson et al., 2020). As the North Pacific High expands during the transition between winter and summer, these storms are suppressed and the local wind follows the prevailing wind patterns which are northwest (Bakri and Jackson, 2019; Stahl et al., 2006). These dominant directions align closely with the primary axis of the SoG, and further topographic steering constrains the local wind to blow primarily along-axis (Bakri et al., 2017a). A significant exception to this climatology are the winter gap winds that occur in the Fraser River Valley and Howe Sound (Bakri et al., 2017b; Jackson, 1996; Overland and Walter Jr., 1981).

\subsection{Numerical simulations}

The SalishSeaCast model employed in this study is a quasi-operational, biophysical-coupled, Salish Sea configuration of the Nucleus for European Modelling of the Ocean (NEMO) 3.6 engine, developed and maintained by the UBC Mesoscale Ocean and Atmospheric Dynamics (MOAD) Laboratory (Olson et al., 2020; Soontiens and Allen, 2017; Soontiens et al., 2016). NEMO is a finite difference, curvilinear, hydrostatic, primitive equation ocean model with extensive functionality for coupling additional system components such as biogeochemistry, passive tracers, Lagrangian particles and sea ice (Madec et al., 2017). The SalishSeaCast domain has approximately $500 \mathrm{~m}$ horizontal resolution and $40 z$-coordinate layers approximately $1 \mathrm{~m}$ thick near the surface, coarsening to $27 \mathrm{~m}$ in the bottom layer with partial steps at the bottom boundary. The model uses split-explicit time stepping with barotropic and baroclinic time steps of $2 \mathrm{~s}$ and $40 \mathrm{~s}$, respecively. A $2 \mathrm{~s}$ vertical time step is also specified to maintain stability in the tidal mixing regions where vertical velocities are large. Lateral mixing is constrained by constant horizontal eddy viscosity and diffusivity values of $1.5 \mathrm{~m}^{2} \mathrm{~s}^{-1}$, and vertical mixing is parameterized using a $k$ - $\epsilon$ turbulence closure scheme with background vertical eddy viscosity and diffusivity values of $1 \times 10^{-6} \mathrm{~m}^{2} \mathrm{~s}^{-1}$. Partial slip conditions are imposed at lateral closed boundaries, and quadratic bottom friction and a log layer parameterization are imposed at the bottom boundary.

The SalishSeaCast ecosystem model, SMELT (Salish Sea Model Ecosystem-Lower Trophic), is a nutrient-phytoplanktonzooplankton-detritus (NPZD) scheme coupled to the physics engine using the NEMO Tracers in the Ocean Paradigm (TOP) module (Olson et al., 2020). SMELT simulates the dominant functional groups of the Salish Sea, specifically: 3 nutrient classes (nitrate, ammonium, silica), 3 phytoplankton classes (diatoms, small flagellates, Mesodinium rubrum), 2 grazer classes (microzooplankton, mesozooplankton) and 3 detrital pools (biogenic silica, particulate organic nitrogen, dissolved organic nitrogen). M. rubrum is a mixotrophic ciliate that can contribute significantly to observed phytoplankton biomass in the Salish Sea, and both the autotropic and heterotrophic behaviors attributed to this ciliate are simulated in the model.

Open boundaries in Juan de Fuca Strait and Johnstone Strait are forced with eight tidal constituents (K1, O1, P1, Q1, M2, K2, N2, S2) determined according to Foreman et al. (2000) and Thomson and Huggett (1980), respectively. Surface height is additionally forced at the Juan de Fuca boundary using a storm surge forecast at Neah Bay, USA provided by the United States National Oceanic and Atmospheric Administration (NOAA). The Flather radiation condition (Flather, 1994) is used for 
https://doi.org/10.5194/os-2021-21

Preprint. Discussion started: 1 April 2021

barotropic tidal velocities and sea surface height, a modified Orlanski radiation condition (Marchesiello et al., 2001) with a sponge layer is used for baroclinic velocities, and the Flow Relaxation Scheme (Madec et al., 2017) is used for temperature and salinity within 10 grid points from the boundary. Temperature, salinity and nitrate at the Juan de Fuca open boundary are obtained from detided outputs of the University of Washington LiveOcean model (Fatland et al., 2016). Dissolved silica is further estimated from LiveOcean nitrate (Olson et al., 2020). Temperature, salinity, nitrate and silica at the Johnstone Strait boundary are set based on monthly climatologies provided by the Hakai Institute. Ammonium at both boundaries is set to a mean observed profile (Olson et al., 2020).

Surface momentum, heat, precipitation, and sea level pressure are forced with results from the High Resolution Deterministic

Prediction System (HRDPS), which is a $2.5 \mathrm{~km}$ operational Pan-Canadian weather forecast model developed and maintained by Environment and Climate Change Canada (ECCC) (Milbrandt et al., 2016). Wind stress $\vec{\tau}$ is calculated according to a quadratic wind speed parameterization

$\vec{\tau}=\rho_{\mathrm{a}} C_{\mathrm{s}} U \mathbf{U}$

where $\mathbf{U}$ is the surface wind velocity vector, $U$ is the surface wind speed, $\rho_{\mathrm{a}}$ is the surface air density and $C_{\mathrm{s}}$ is the surface drag coefficient calculated according to Hellerman and Rosenstein (1983). The wind stress boundary condition is applied to the surface momentum via the vertical momentum flux equation

$$
\frac{\vec{\tau}}{\rho_{0}}=\left.A_{v} \frac{\partial \mathbf{u}_{h}}{\partial z}\right|_{z=1}
$$

where $\mathbf{u}_{h}$ is the horizontal fluid velocity vector, $A_{v}$ is the vertical eddy diffusivity determined by the $k$ - $\epsilon$ parameterization, $\rho_{0}$ is the background density and $z$ is the vertical coordinate.

Monthly climatologies are used to prescribe runoff from the approximately 150 rivers included in the model domain (Morrison et al., 2012). Upper Fraser River runoff is prescribed separately using daily observations provided by ECCC from a flow gauge approximately $150 \mathrm{~km}$ upstream at Hope, BC while the lower Fraser tributaries are included in the climatologies. Temperature in all rivers is set according to a monthly climatology of Fraser River temperature based on ECCC observations at Hope (Allen and Wolfe, 2013), and river salinity is set to zero. Biological river tracers are determined according to ECCC and UBC observations in selected watersheds including the lower Fraser (Olson et al., 2020). For example, Fraser River nitrate is set to a seasonal cycle that varies between $8.37 \mu \mathrm{M} \mathrm{N}$ during the winter and $2.88 \mu \mathrm{M} \mathrm{N}$ during the freshet.

The tidal constituents at the open boundaries have been tuned to improve model skill at 31 tidal gauges located throughout the model domain (Soontiens et al., 2016). This tuning exercise prioritized high skill in the SoG region, and the tidal predictions outside of the SoG are thus less accurate. However, tidal mixing between Juan de Fuca Strait and the SoG is sufficiently accurate to resolve deep basin flushing, which is important for controlling temperature and salinity in the SoG over time (Soontiens and Allen, 2017). Soontiens and Allen (2017) further determined that the largest improvements to deep flushing were achieved by removing a numerical kinetic energy sink artifact known as the Hollingsworth instability (Hollingsworth et al., 1983). Temperature, salinity and the biological tracers have been rigorously evaluated against observations from several comprehensive, multi-year sampling programs covering the full model domain (Olson et al., 2020). Temperature is the most 
accurately predicted tracer with no significant bias. Salinity is predicted nearly as accurately as temperature except at low salinity, especially near the coast where the limitations of the monthly watershed climatology become important and coastal processes like wetting and drying are unresolved in the model. Model nitrate, dissolved silica and chlorophyll all demonstrate average to strong skill relative to similar models of the study region (e.g., Khangaonkar et al., 2018), with nitrate performing the strongest of the three tracers. Surface nitrate in the SoG is biased low by approximately $1-2 \mu \mathrm{M}$ during the productive season since model phytoplankton are slightly more effective at depleting surface nutrients than observed communities. This phenomenon is common in biological models of the SoG (e. g., Moore-Maley et al., 2016).

A 5-year hourly hindcast record of the SalishSeaCast model was obtained by performing parallel CPU runs on a high performance computing platform. A restart file was produced by initializing the model tracers according to several data sets and spinning up from rest over a one-year period (Olson et al., 2020). This restart file was then used to initialize the hindcast. We limit our analysis to the productive season between spring and fall when the surface nitrate is depleted. We define these seasonal bounds using a nitrate threshold of $2 \mu \mathrm{M}$ applied to the spatially averaged surface nitrate concentration over the SoG sub-region. Specifically, the analysis window begins 5 days after the surface nitrate first drops below the threshold value and ends 5 days before the surface nitrate last rises above the threshold value. The 5-day buffer is included to further eliminate the biological influence of large blooms on the upwelling signal.

\subsection{Principal component analysis}

We perform principal component analysis (PCA) as described by Preisendorfer (1988) on the hourly surface nitrate and temperature records during the seasonal windows defined by the $2 \mu \mathrm{M}$ nitrate threshold. We only consider the region including the SoG and the tidal mixing areas (Fig. 1), and we re-sample the model grid to a resolution of $2.5 \mathrm{~km}$ in order to improve computation time. The sub-sampled nitrate and temperature records are "de-trended" by subtracting the low-pass filtered signal. This signal is obtained using a finite impulse response (FIR) filter with a $1235 \mathrm{~h}$, or approximately $50 \mathrm{~d}$, Blackman window. The $1235 \mathrm{~h}$ Blackman window attenuates the signal 10-fold at an effective $841 \mathrm{~h}$ or approximately $35 \mathrm{~d}$ cutoff frequency, which is sufficient to remove any seasonal scale climatological variability but long enough to retain the effects of low frequency tidal variations.

The sub-sampled spatial grid points are treated as a set of $p$ independent variables over a time series of length $n$ such that each tracer record is reshaped to an $n \times p$ matrix $\mathbf{Z}$. The principal component (PC) loadings and empirical orthogonal functions (EOF) are obtained using the singular value decomposition of $\mathbf{Z}$

$\mathbf{Z}=\mathbf{A}^{\prime} \mathbf{L}^{1 / 2} \mathbf{E}^{\mathrm{T}}=\mathbf{A} \mathbf{E}^{\mathrm{T}}$

where $\mathbf{A}$ is the $n \times p$ PC loadings matrix, $\mathbf{L}$ is the $p \times p$ triangular eigenvalue matrix and $\mathbf{E}$ is the $p \times p$ EOF pattern matrix. The orthogonality constraint of PCA can limit the extent to which each mode of variability actually captures the full pattern of a given physical phenomenon. We thus introduce a $p \times p$ rotation matrix $\mathbf{R}$ such that

$\mathbf{Z}=\mathbf{A}\left(\mathbf{R R}^{\mathrm{T}}\right) \mathbf{E}^{\mathrm{T}}=(\mathbf{A R})(\mathbf{E R})^{\mathrm{T}}=\mathbf{B} \mathbf{U}^{\mathrm{T}}$ 
where $\mathbf{B}$ is the rotated $n \times p$ PC loading matrix and $\mathbf{U}$ is the rotated $p \times p$ EOF pattern matrix. $\mathbf{R}$ is chosen such that the varimax criterion

$f(\mathbf{R})=\sum_{j=1}^{p}\left\{\frac{1}{n} \sum_{t=1}^{n}\left[b_{j}^{2}(t)\right]^{2}-\left[\frac{1}{n} \sum_{t=1}^{n} b_{j}^{2}(t)\right]^{2}\right\}$

is maximized (Kaiser, 1958), where $b_{j}(t)$ are the elements of $\mathbf{B}$ (Preisendorfer, 1988, ch. 7d). We use the algorithm described by Horst (1965, ch. 18.4) in order to find $\mathbf{R}$.

\subsection{Analysis and Visualization}

SalishSeaCast results and HRDPS forcing data were stored and accessed in the Network Common Data Form (NetCDF) format (Unidata, 2019). All analysis and visualization was performed using Python 3.9 and the Jupyter development environment (Kluyver et al., 2016). In addition to the Python standard library, the following packages were used: Xarray for NetCDF processing (Hoyer and Hamman, 2017), NumPy for arrays, matrix operations, filtering and spectral analysis (Harris et al., 2020), Pandas for loading and processing observed wind data (McKinney, 2010), Matplotlib for plotting (Hunter, 2007), Cartopy for map projections (Met Office, 2010-2015) and Windrose for polar histograms (Roubeyrie and Celles, 2018).

\section{Results}

\subsection{Overview of 5 year record and comparisons with observations}

In order to illustrate how SalishSeaCast resolves upwelling in the SoG, we first compare snapshots of hindcast surface temperature and nitrate with surface temperature observations from the Moderate Resolution Imaging Spectroradiometer (MODIS) instrument aboard the NASA Aqua satellite. We selected four cloud-free images that overlap with sustained, along-axis wind events during the hindcast period. Two of these images were taken during southeast wind (2015 Sep. 4 and 2018 Sep. 12) and two were taken during northwest wind (2016 Jul. 30 and 2019 Jun. 20). In all four images, a cross-axis gradient to the right of the wind direction is clearly visible in the MODIS surface temperature observations (Fig. 2, top row), and the dominant spatial features of these gradients are reproduced in the SalishSeaCast surface temperature fields (Fig. 2, middle row). These features include a cold coastal upwelling band to the left of the wind direction, offshore and downwind advection of the upwelling plume, and along-axis variability. The cold upwelling regions of the surface temperature fields also overlap with positive nitrate anomalies in the SalishSeaCast surface nitrate fields (Fig. 2, bottom row). From these four snapshots, upwelling appears to be consistently strong in specific areas and weak or patchy in others. Along the eastern shore, upwelling is strongest in the northern and central SoG and the northern tip of Texada Island, and weakens significantly in the southern SoG near the Fraser River mouth. Along the western shore, upwelling is most prominent in the northern SoG near Baynes Sound. In addition, large nitrate plumes appear to be advected northward from the Gulf Islands region where tidal mixing is strong.

We next compare the 5 year HRDPS hourly surface wind velocity record with 5 years of hourly wind velocity observations at the four open water, meteorological observing stations shown in Fig. 1 (magenta symbols). Sand Heads and Sisters Islet are 
https://doi.org/10.5194/os-2021-21

Preprint. Discussion started: 1 April 2021

navigational light stations equipped with meteorological sensors maintained by ECCC, while Halibut Bank and Sentry Shoal are $3 \mathrm{~m}$ discus buoys maintained by the Department of Fisheries and Oceans Canada (DFO). At all four stations, an alongaxis wind climatology dominates the observed wind velocity record in winter (Fig. 3, top row) and summer (Fig. 3, second row from bottom), and the primary features of this record are reproduced by the HRDPS wind velocities (Fig. 3, second row from top and bottom row). In addition to along-axis dominance, these features include a seasonal separation between strong southeasterly winter wind and weaker northwesterly summer wind. There is also a tendency for stronger winter southeasterlies in the northern SoG, however the summer northwesterlies do not show a similar along-axis variation. The along-axis dominance of these records is consistent with both the established wind climatology and topographic steering discussed in Sec. 2.1 and
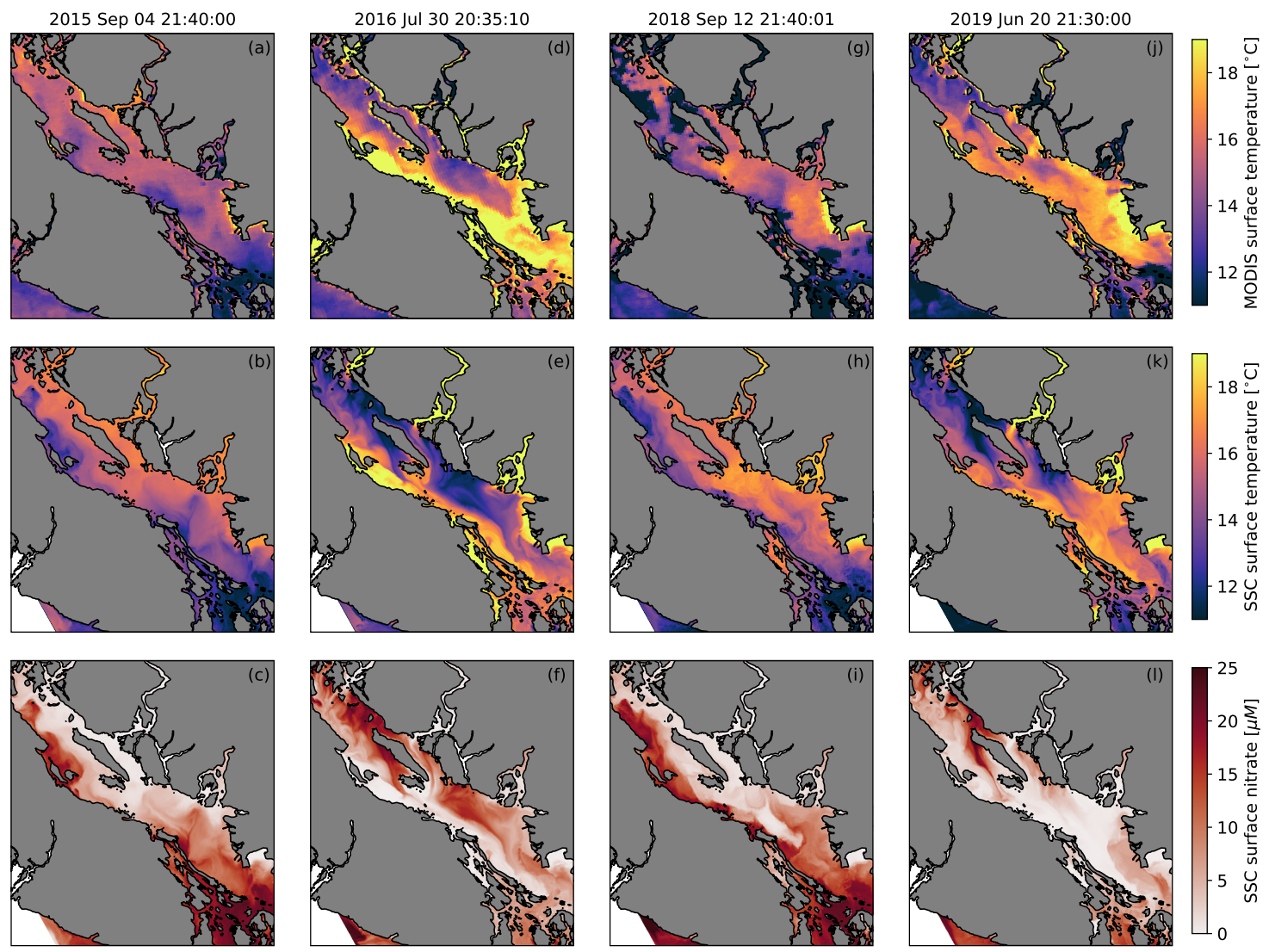

Figure 2. Surface temperature observations from the Moderate Resolution Imaging Spectroradiometer (MODIS) instrument aboard the NASA Aqua satellite (a-d), SalishSeaCast (SSC) surface temperature (e-h) and SSC surface nitrate (i-l) during four cloud-free upwelling events. All times are in UTC. The surface fields shown on 2015 September 4 and 2018 September 12 occurred during southeasterly wind and show cold, nitrate-rich upwelling along the Vancouver Island coast, while the surface fields shown on 2016 July 30 and 2019 June 20 occurred during northwesterly wind and show upwelling along the opposing BC mainland coast and the western side of Texada Island. The SSC fields reproduce the overall spatial structure observed in the MODIS images. 
https://doi.org/10.5194/os-2021-21

Preprint. Discussion started: 1 April 2021

(c) Author(s) 2021. CC BY 4.0 License.

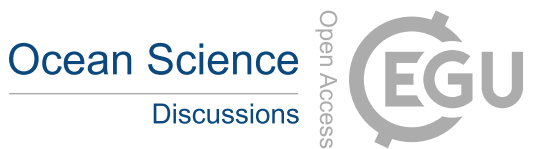

(c) (i)
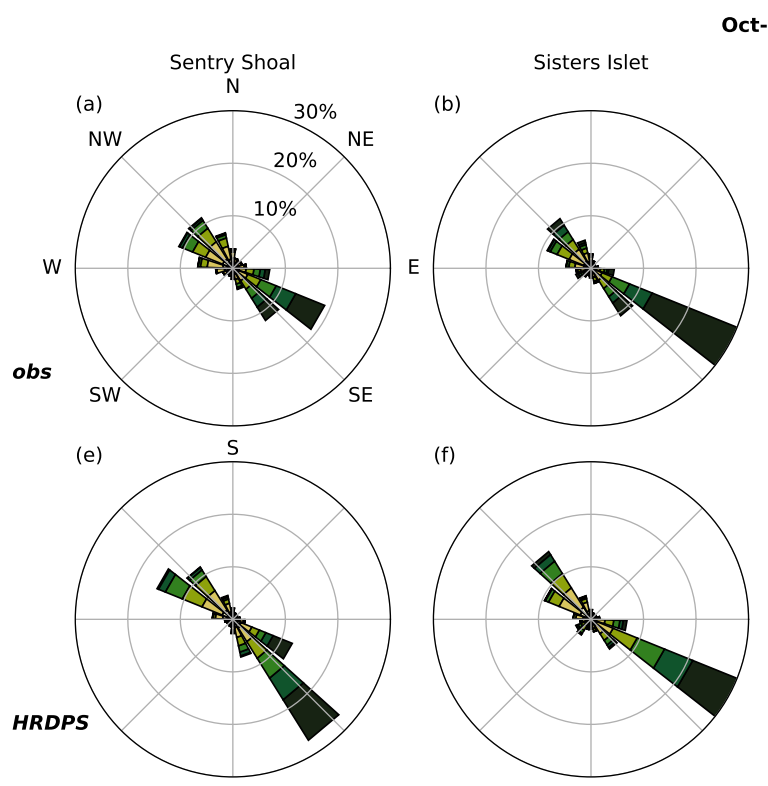

oct-Mar
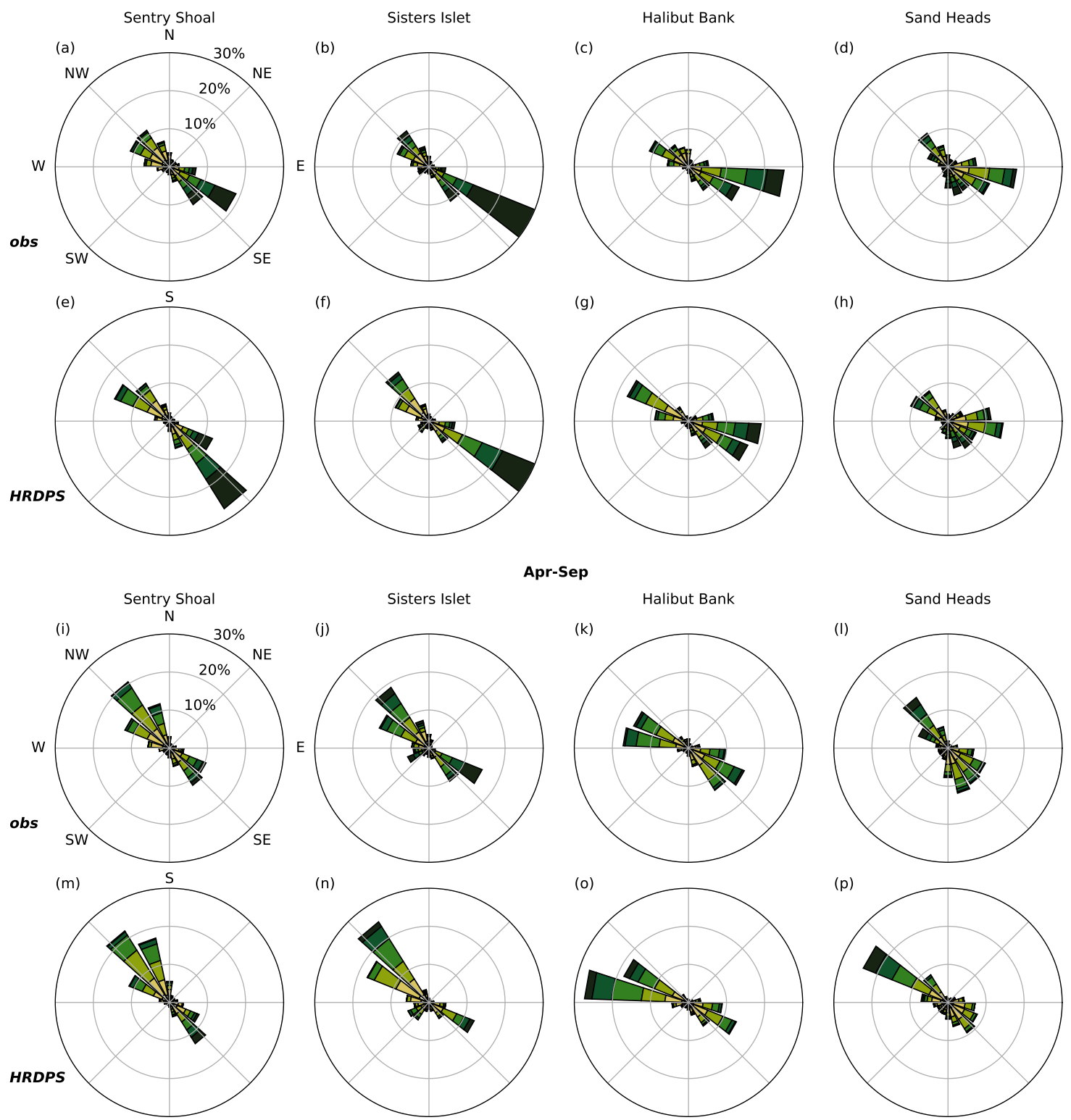

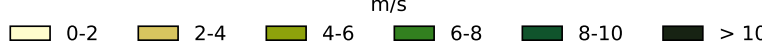

Figure 3. Condensed hourly wind station observations and hourly HRDPS results for the 2015 through 2019 period at Sentry Shoal (left column), Sisters Islet (second from left), Halibut Bank (second from right) and Sand Heads (right column). Data are binned by direction from and relative frequency of occurrence is given by the radial magnitude of each bin. Overall, the HRDPS wind record reproduces the observed, along-axis wind climatology at all stations. The seasonal wind separation of strong winter southeasterlies and weaker summer northwesterlies is also reproduced. 
https://doi.org/10.5194/os-2021-21

Preprint. Discussion started: 1 April 2021

provides significant physical driver for upwelling in the SoG. Additionally, the seasonal variation between winter and summer is consistent with the winter storm activity of the region.

With the along-axis wind climatology established, we now turn our focus to the 5 year SalishSeaCast nitrate and temperature records. We first examine these records at the four representative horizontal grid locations shown in Fig. 1 (colored stars). Two of these locations are located near the tidal mixing regions in the northern and southern SoG (Discovery Passage and Boundary Pass, respectively), and the other two are located along the eastern and western coastlines in the central SoG (Texada and Central VI, respectively). At all four locations, surface nitrate and temperature exhibit seasonal cycles that follow the expected cycles of wind, solar and freshwater forcing described in Sec. 2.1 (Fig. 4). During winter when we anticipate elevated storm activity, surface nitrate is high and surface temperature is low. During summer when we anticipate strong stratification and biological nutrient uptake, surface nitrate decreases and surface temperature increases. The tidal mixing locations at Discovery Passage and Boundary Pass remain nitrate replete and cold throughout the summer, while the central locations at Texada and Central VI are more nitrate-depleted and warmer. The seasonality of wind speed and direction is reflected in the along-axis HRDPS wind speed averaged over the SoG region (Fig. 4, gray patch). Strong positive, or southeasterly, wind events dominate during the winter while weaker negative, or northwesterly, wind events dominate during the summer.

Both surface nitrate and temperature fluctuate more strongly in summer compared to winter because of the seasonal vertical gradients, nitricline and themocline respectively, that form in spring and erode in autumn. These gradients are visible in the seasonal median profiles of nitrate and temperature over the 5 year record at each of the four SalishSeaCast grid locations (Fig. 5, top row). The seasonal median window is defined according to the $2 \mu \mathrm{M}$ nitrate threshold described in Sec. 2.2, and shown by the gray dashed lines in Fig. 4. Vertical gradients are weaker and shallower in the tidal mixing regions at Discovery Passage and Boundary Pass relative to the central locations at Texada and Central VI. At Texada and Central VI the gradients are stronger, however the nitricline is approximately 5-10 m deeper than the thermocline and the surface nitrate interquartile range is nearly zero while the temperature interquartile range is largest at the surface. These differences between the vertical structure of nitrate and temperature are consistent with the more episodic surface nitrate pulses relative to the more periodic surface temperature variations (Fig. 4). Additionally, the seasonal nitricline is established earlier than the seasonal thermocline since the spring diatom bloom precedes the period of maximum stratification and solar heating. This delay in thermocline development is reflected in the slow warming of the surface locations (Fig. 4, right column) relative to the rapid spring nitrate drawdown (Fig. 4, left column). There is also a small but significant cross-axis asymmetry where both the nitricline and thermocline are up to $5 \mathrm{~m}$ shallower on the eastern side of the basin at Texada relative the western side at Central VI (Fig. 5b, c). This asymmetry is consistent with the cross-axis stratification gradient mentioned in Sec. 2.1.

Regardless of the differences between surface nitrate and surface temperature, large fluctuations in both quantities along the basin sides at Texada and Central VI overlap with directional wind events in a manner consistent with upwelling (Fig. 4). Specifically, nitrate pulses along the eastern shore at Texada occur during northwesterly wind events and nitrate pulses along the western shore at Central VI occur during southeasterly wind events. These events occur in the surface temperature record as cold pulses. However, the periodic forcing mechanisms like tides and diurnal heating may also be embedded in these pulses to some degree and tides certainly dominate at Discovery Passage and Boundary Pass. Power spectra of the surface nitrate and 
https://doi.org/10.5194/os-2021-21

Preprint. Discussion started: 1 April 2021 well as smaller but distinct peaks at the fortnightly and monthly frequencies (Fig. 5, bottom rows). These distinct peaks are
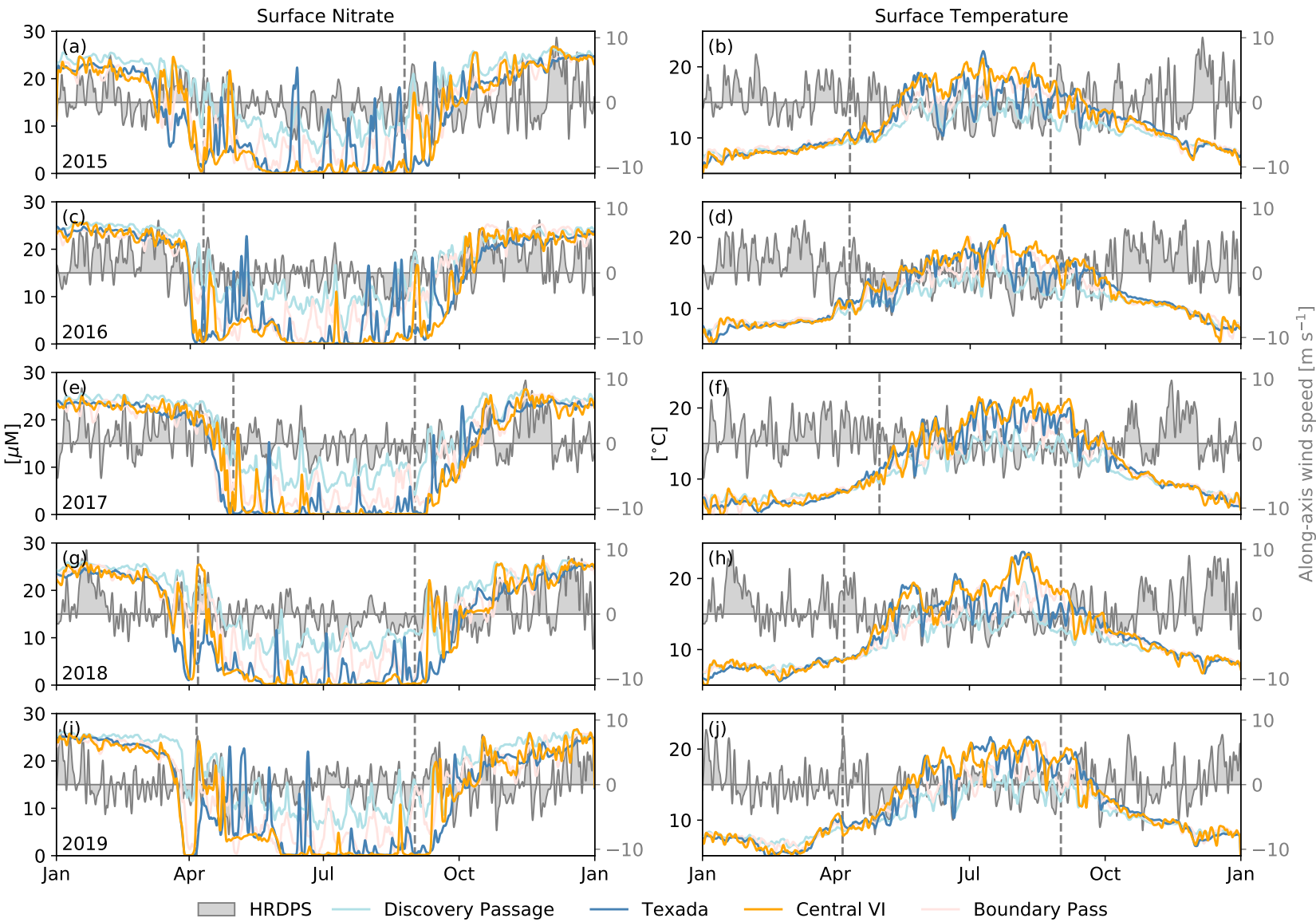

Figure 4. Time series of the SalishSeaCast hourly surface nitrate (left column) and surface temperature (right column) records during 2015-2019 at the 4 coastal locations shown in Fig. 1. The HRDPS hourly along-axis surface wind speed record averaged over the Strait of Georgia region is also shown. The nitrate, temperature and wind speed records have been low-pass filtered using a 3-day Blackman window to emphasize the subtidal variability. The Texada and Central Vancouver Island (VI) locations are positioned along the respective eastern and western shores of the Strait of Georgia where upwelling dominates, while the Discovery Passage and Boundary Pass locations are positioned at the northern and southern ends of the basin where tidal mixing dominates. The seasonal wind climatology between winter southeasterlies (positive) and summer northwesterlies (negative) is apparent from the spatially averaged HRDPS record. The characteristic biological summer surface nitrate drawdown is also apparent, and is interrupted by wind driven upwelling pulses at Central VI and Texada. The temperature cycle follows the solar heating cycle with cold, wind driven upwelling pulses at Central VI and Texada that co-occur with the nitrate pulses. Surface nitrate is never fully depleted in the tidal mixing regions. 

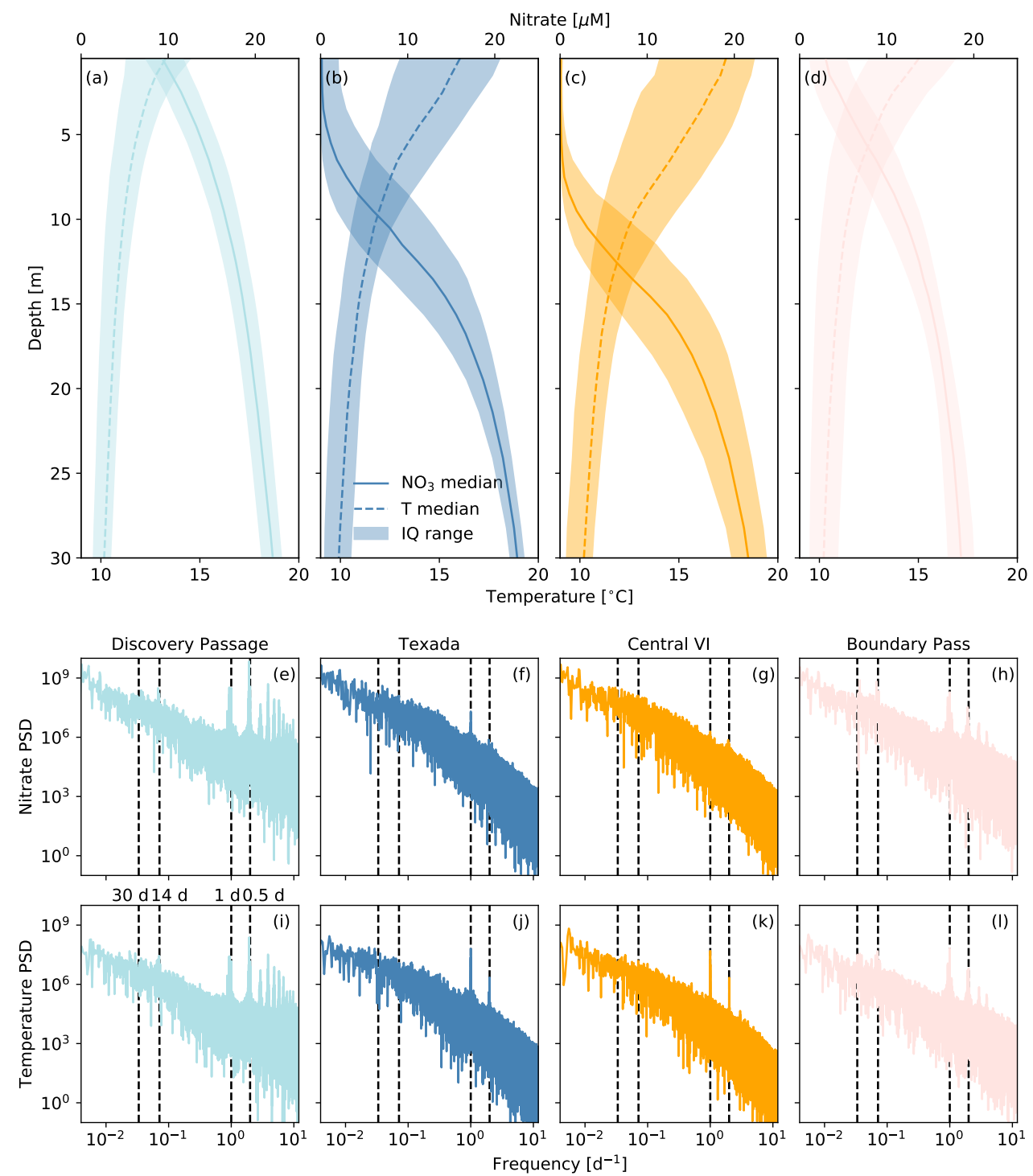

_ Discovery Passage

Texada

- Central VI

Boundary Pass

Figure 5. Median depth profiles of SalishSeaCast nitrate $\left(\mathrm{NO}_{3}\right)$ and temperature $(\mathrm{T})$ during the productive seasons of $2015-2019$ at the 4 coastal locations shown in Fig. 1 (top row). The seasonal cutoffs for each year are shown in Fig. 4 and the interquartile (IQ) range across each season is also shown. The nitrate and temperature profiles are more uniform and less variable in the tidal mixing regions (a, d) than in the upwelling-dominated regions (b, c). In the upwelling regions, the nitricline and thermocline are slightly shallower on the eastern side of the basin at Texada (b) than on the western side at Central VI (c). Power spectra of SalishSeaCast surface nitrate (middle row) and surface temperature (bottom row) during the entire 2015-2019 record are included below the profiles (PSD = power spectral density). Semidiurnal, diurnal, fortnightly and monthly frequencies are indicated by vertical dashed lines. Significant tidal energy is apparent in the tidal mixing regions at Discovery Passage and Boundary Pass, but is largely absent at the upwelling-dominated Central VI and Texada locations. Additionally, the diurnal heating signal is visible in the temperature spectra at the non-tidal locations ( $\mathrm{j}, \mathrm{k})$. 
https://doi.org/10.5194/os-2021-21

Preprint. Discussion started: 1 April 2021

largely absent at Texada and Central VI and the low frequency energy is more broadly distributed, with the major exception of a strong diurnal heating peak in the surface temperature spectra.

\subsection{Principal component analysis}

When principal component analysis is applied to the de-trended surface nitrate and temperature records during the seasonal nitrate threshold windows shown in Fig. 4, approximately half of the variance is explained by the first 3 modes (Fig. 6). However, the variance distribution across these modes and the physical interpretation of the EOF spatial patterns is different for each record. For surface nitrate the variance is distributed approximately equally across the 3 modes, which represent in order of decreasing variance, upwelling along the western shore (mode 1), tidal mixing near the basin ends (mode 2) and upwelling along the eastern shore (mode 3). When the same analysis is applied to surface temperature, a mixing-heating pattern dominates the variance (mode I) followed by two cross-axis patterns (modes II and III). The nitrate and temperature EOF modes can be considered as anomalies superimposed on the seasonal median surface fields (Figs. 6a and e). In this context, the small amplitude of the nitrate EOF mode 2 is a tidal modulation of the background elevated nitrate concentration in the tidal mixing regions. Conversely, the more wind and solar driven modes (nitrate modes 1 and 3, temperature mode I) have vanishing amplitudes in the tidal mixing regions.

The nitrate and temperature PC loadings time series behave consistently with the physical interpretations of their EOF counterparts (Fig. 7). The western shore nitrate upwelling mode 1 spikes during sustained positive along-axis (southeasterly) wind events, while the eastern shore nitrate upwelling mode 3 spikes during sustained negative along-axis (northwesterly) wind events. Northwesterly wind also weakly increases the amplitude of mode 1, likely through vertical mixing. Conversely, the tidal nitrate mode 2 demonstrates both high-frequency and subtidal oscillations and no consistent overlap with the alongaxis wind record. The dominant temperature mixing-heating mode I is positive (cold) during along-axis wind events in either direction and negative (warm) when the wind relaxes, with high frequency oscillations indicative of the diurnal heating cycle. The cross-axis temperature modes II and III are positive during northwesterly winds and negative during southeasterly winds, albeit less distinctly than the nitrate modes which is consistent with the larger interquartile range of temperature relative to nitrate near the surface (Fig. 5).

The PC loadings power spectra further support the periodicity observed in the PC loadings time series (Fig. 8, top rows). With respect to nitrate, tidal energy is primarily observed in mode 2, including pronounced fornightly and monthly subtidal peaks. In the remaining nitrate upwelling modes 1 and 3, only smaller tidal peaks are present and the primary energy is more broadly distributed in the subtidal range. The temperature mixing-heating mode I spectrum is similar to nitrate modes 1 and 3 with the exception of a pronounced diurnal heating signal. Temperature mode II is not easily categorized. The EOF pattern exhibits both a cross-axis gradient and significant anomalies in the tidal mixing region (Fig. $6 \mathrm{~g}$ ) while the spectral density shows strong tidal peaks and a broad distribution of subtidal energy (Fig. 8e). The temperature mode III EOF pattern is more clearly cross-axis (Figs. 6h) and the spectral density is more similar to the nitrate upwelling modes 1 and 3 (Fig. 8f), although the explained variance is lower at $6 \%$. 
https://doi.org/10.5194/os-2021-21

Preprint. Discussion started: 1 April 2021
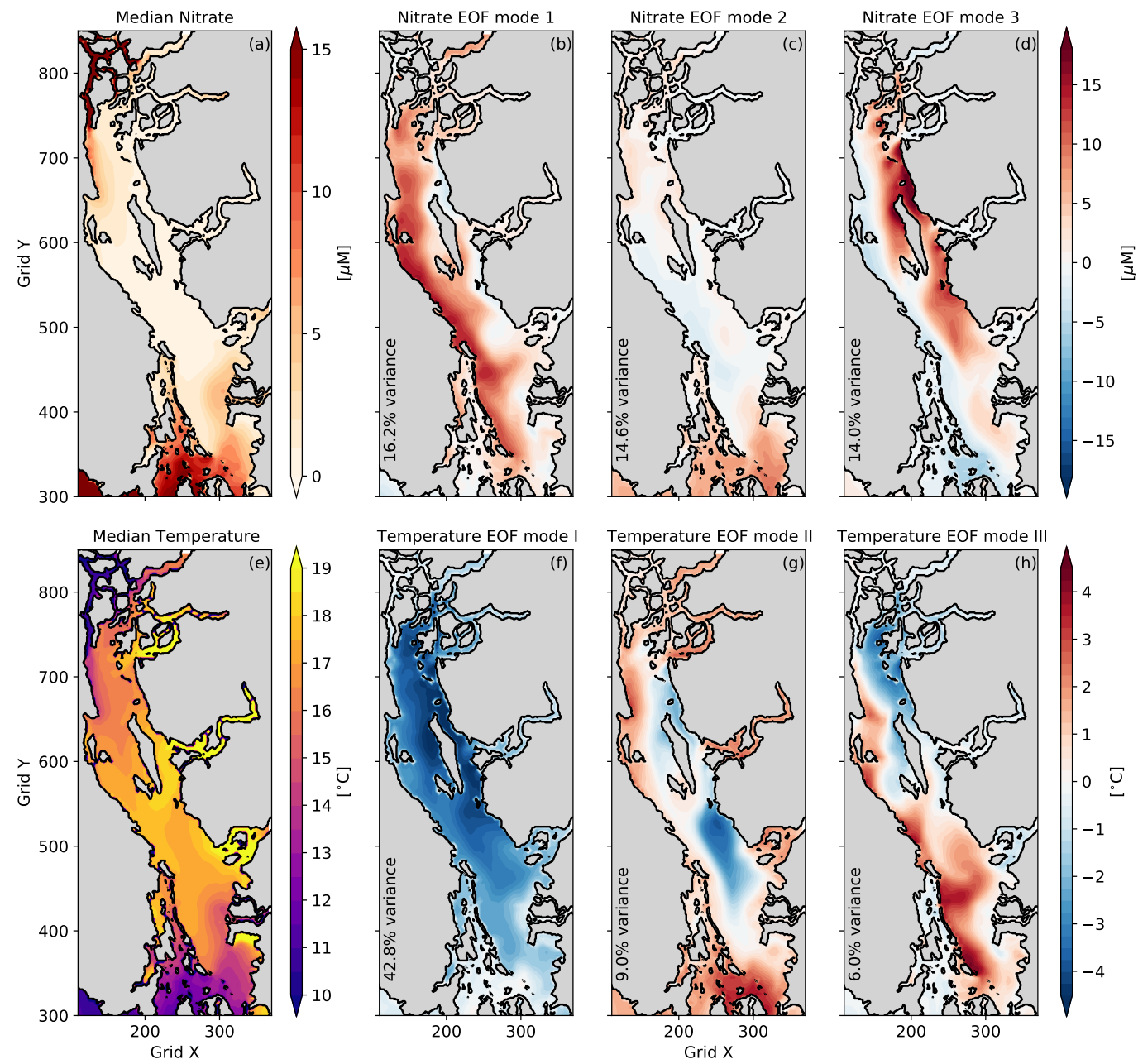

Figure 6. Empirical orthogonal function (EOF) modes in order of decreasing percent variance applied to the 2015-2019 SalishSeaCast surface nitrate (top row) and surface temperature (bottom row) records, between the seasonal cutoffs shown in Fig. 4. The median surface nitrate (a) and temperature (e) fields between the seasonal cutoffs are also shown. The surface fields are subsampled to $2.5 \mathrm{~km}$ resolution and detrended using a $35 \mathrm{~d}$ high-pass Blackman window filter prior to the principal component analysis (Section 2.3). Two cross-axis upwelling modes and one tidal mode dominate the nitrate variance approximately equally (b-d) while the temperature variance is dominated by a single mixing-irradiance mode followed by two cross-axis upwelling modes (f-h). Higher modes contain additional upwelling and tidal variability, however the percent variance of each mode is significantly reduced beyond the third mode.

By evaluating the correlation between the PC loadings and the time-averaged, along-axis wind stress, calculated from HRDPS wind velocity according to Equation 2, we formalize the wind dependence of each PCA mode (Fig. 8, bottom rows). Nitrate upwelling modes 1 and 3 demonstrate clear correlations to southeasterly and northwesterly wind stress, respectively, while the tidal mode 2 does not correlate with wind stress at all. The Pearson correlation coefficients for modes 1 and 3 are 
https://doi.org/10.5194/os-2021-21

Preprint. Discussion started: 1 April 2021

(C) Author(s) 2021. CC BY 4.0 License.
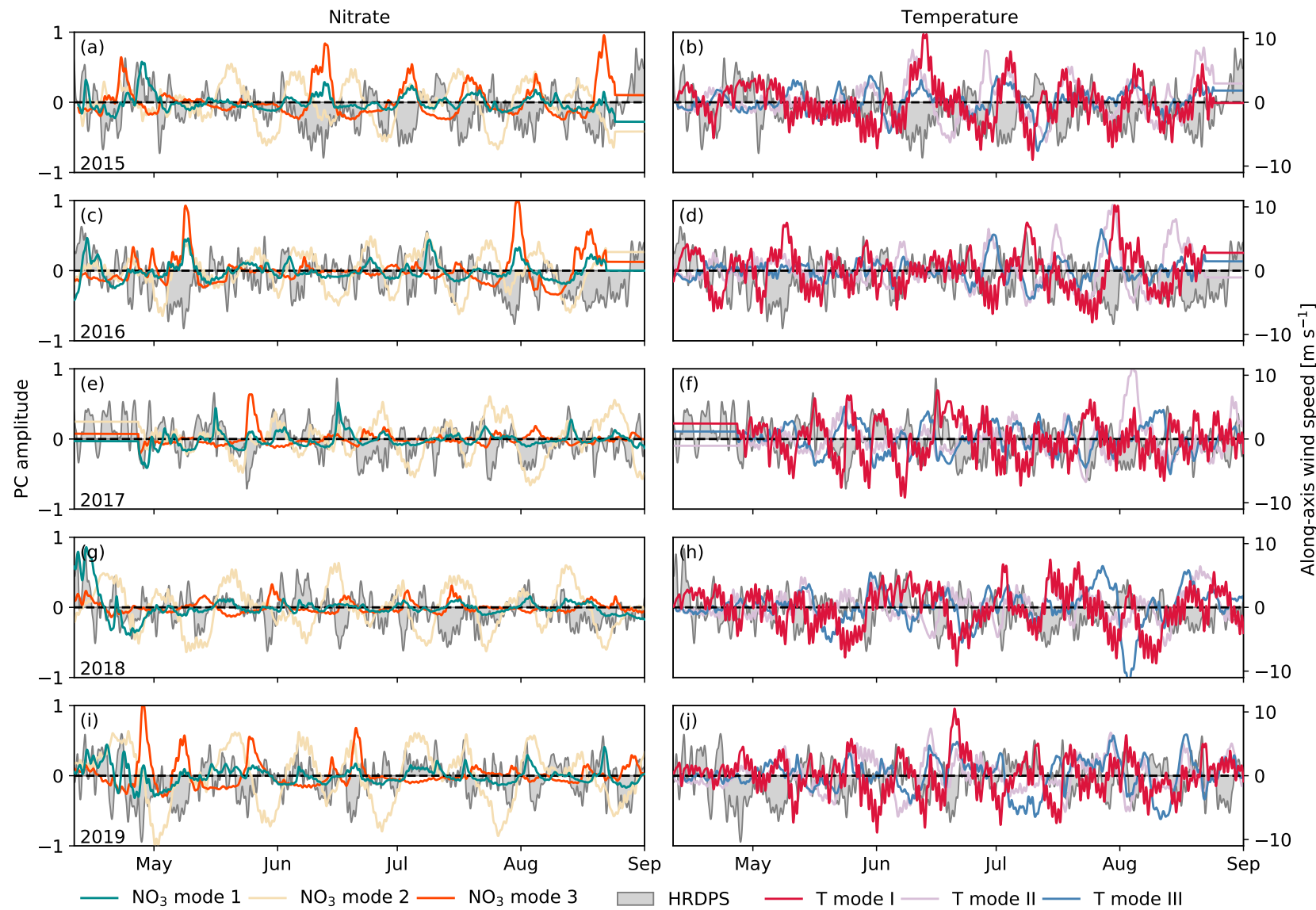

Figure 7. Time series of the first 3 principal component (PC) mode loadings for surface nitrate (left column) and temperature (right column) corresponding to the EOF spatial patterns shown in Fig. 6. Along-axis HRDPS wind speed averaged over the Strait of Georgia region is also shown. The PC and wind timeseries are low-pass filtered using a $1 \mathrm{~d}$ Blackman window cutoff in order to emphasize the low frequency variability. The nitrate upwelling modes $\left(\mathrm{NO}_{3}\right.$ modes 1 and 3$)$ increase in amplitude during sustained wind events, while the tidal nitrate mode $\left(\mathrm{NO}_{3}\right.$ mode 2$)$ is independent of wind entirely. The mixing-heating temperature mode ( $\mathrm{T}$ mode $\mathrm{I}$ ) is positive during sustained wind and negative in the absence of wind when diurnal heating is most effective.

determined using only the wind stress values with the sign of the dominant correlation direction. The small amount of correlation between these modes and the reverse wind stress directions, which we attribute to wind mixing, is thus excluded from the analysis. The correlation is further maximized by choosing a wind stress backward averaging window of $54 \mathrm{~h}$. Since there is no significant correlation for nitrate mode 2, a default $48 \mathrm{~h}$ averaging window is used. With respect to temperature, mixing-heating mode I correlates positively (cold) with both northwesterly and southeasterly time-averaged wind stress - the absolute value of the wind stress is used to calculate the correlation coefficient in this case. The backward averaging window that maximizes the correlation coefficient for this mode is $30 \mathrm{~h}$, which is $1 \mathrm{~d}$ shorter than the averaging window used for the nitrate upwelling 

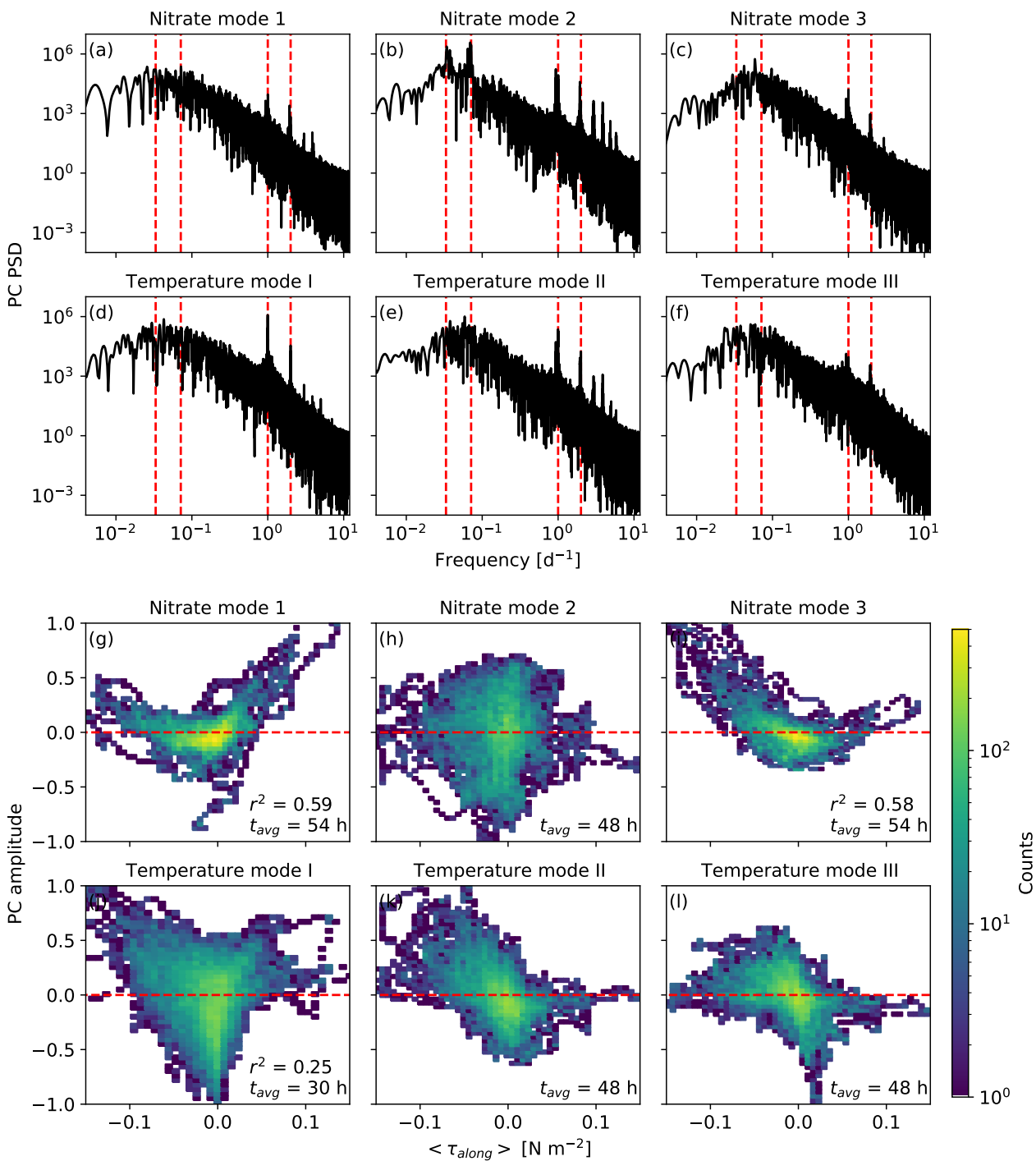

Figure 8. Power spectral density (PSD) of the first 3 principal component (PC) mode loadings for surface nitrate (top row) and temperature (second from top) corresponding to the EOF spatial patterns shown in Fig. 6. Monthy, fornightly, diurnal and semidiurnal frequencies are shown as red dashed lines. The tidal energy in nitrate mode 2 is apparent (b) as is the diurnal heating signal in temperature mode I (d), while the subtidal energy in the remaining modes is more broadly distributed. Included below the spectra are PC loadings of nitrate (second from bottom) and temperature (bottom) versus temporally back-averaged, along-axis wind stress calculated from spatially-averaged HRDPS wind speed according to Equation 2. The time averaging window is selected to maximize the Pearson correlation coefficient between the PC record and the wind stress. The correlation coefficients for nitrate modes 1 and 3 are determined using only the wind stress values with the sign of the dominant correlation direction. Correlations for nitrate mode 2 and temperature modes II and III are weak and thus not reported - a default back-averaging window of $48 \mathrm{~h}$ is used in those cases. Nitrate modes 1 (g) and 3 (i) are correlated, respectively, with positive and negative along-axis wind stress over a $54 \mathrm{~h}$ averaging window while temperature mode $\mathrm{I}(\mathrm{j})$ is correlated with the overall wind stress magnitude over a $30 \mathrm{~h}$ averaging window. 
modes. The cross-axis temperature modes II and III visibly correlate positive (cold) with northwesterly wind stress and negative (warm) with southeasterly wind stress. However, since these correlations are weak and the percent variances associated with these modes are low, we have not attempted to quantify the correlation and use the default $48 \mathrm{~h}$ wind stress backaverage for visualization only. While these weak correlations are indicative of wind dependence to some degree, the unclear EOF spatial patterns and PC spectra prevent us from drawing meaningful conclusions about modes II and III. Additionally, given the low percent variances explained by these higher temperature modes relative to mode I, we assign them secondary importance and do not discuss them further.

\section{Discussion}

\subsection{Modes of upwelling}

To provide a mechanistic context to the cross-axis upwelling response observed in the PCA results, consider a wind forced, two layer, shallow water approximation of a rectangular basin as described by Csanady (1982). Assuming that baroclinic motions dominate the momentum balance, the lower layer transports are equal and opposite to the upper layer transports and the interface displacement $\zeta$ is coupled to the surface displacement $\eta$ according to

$\eta=-\frac{\Delta \rho}{\rho_{0}} \frac{h_{1}+h_{2}}{h_{2}} \zeta$

where $\Delta \rho, \rho_{0}, h_{1}$ and $h_{2}$ retain their previous definitions from Equation 1. This coupling between the upper and lower layers results in a single set of momentum and continuity balances for the lower layer cross-shore and along-shore transports, $U$ and $V$, respectively

$$
\begin{aligned}
\frac{\partial U}{\partial t}-f V & =-g^{\prime} h_{1} \delta_{h} \frac{\partial \zeta}{\partial x}-F_{x} \\
\frac{\partial V}{\partial t}+f U & =-g^{\prime} h_{1} \delta_{h} \frac{\partial \zeta}{\partial y}-\delta_{h} \frac{\tau}{\rho_{0}}-F_{y} \\
360 \frac{\partial U}{\partial x}+\frac{\partial V}{\partial y} & =-\frac{\partial \zeta}{\partial t}
\end{aligned}
$$

where $x, y$ and $t$ are the respective cross-axis, along-axis and time coordinates, $g^{\prime}=g \Delta \rho / \rho_{0}$ is the reduced gravitational acceleration across the interface, $\tau$ is the along-axis wind stress and $F_{x}$ and $F_{y}$ are the cross-axis and along-axis bottom friction terms. The thickness ratio $\delta_{h}=h_{2} /\left(h_{1}+h_{2}\right)$ determines the amount of coupling between the surface forcing $\tau$ and the lower layer motions. For a deep SoG, assume $h_{1} / h_{2}<<1$ and $\delta_{h} \approx 1$. Assume negligible bottom friction as well, except in the case of the growing coastal jet that we will discuss shortly.

The balance between the wind stress term and the pressure gradient force term is a recurring element in solutions to Equation 8 and can be summarized by the bulk Richardson number $R i=g^{\prime} h_{1} \rho_{0} / \tau$. Additionally, there are three fundamental length scales to consider: the along-axis length $L_{\mathrm{A}}$, the cross-axis length $L_{\mathrm{C}}$ and the internal Rossby deformation radius $L_{\mathrm{R}}$ (Equation 1). Near a coastline, $L_{\mathrm{R}}$ represents the transition between pressure gradient dominance in the near-shore region and 
Ekman flux dominance in the offshore region. Naturally, if $L_{\mathrm{C}} / L_{\mathrm{R}}<<1$ then pressure gradients dominate everywhere and steady Ekman fluxes cannot develop.

Let us explore two simple cases for wind driven upwelling within this two layer model. Case 1 considers interface displacements along the sides and ends of the basin as infinite coast approximations. This case is analogous to either a dynamically wide basin with $L_{\mathrm{C}} / L_{\mathrm{R}}>>1$ or the early stages of the wind response before the surrounding coasts become significant. Case 2 considers interface displacements constrained by the presence of all four coastal boundaries. This case is analogous to either a dynamically narrow basin with $L_{\mathrm{C}} / L_{\mathrm{R}}<<1$ or the later stages of the wind response after the surrounding coasts become significant. For consistency, assume that $x$ increases to the east and $y$ increases to the north, with the southwest corner defined by $x=0, y=0$. Further define $\tau$ as positive, or toward the north.

\section{Case 1: Upwelling along an infinite coast}

Consider first the coast along the side of the basin at $x=0$ and neglect all along-axis gradients. After an initial spin-up period over which the offshore acceleration $\partial U / \partial t \rightarrow 0$, the surface wind stress drives a growing along-shore jet near the coastal $U=0$ boundary condition and a steady offshore Ekman flux far from the coast where $\partial \zeta / \partial x \rightarrow 0$. Since the growing alongshore jet is in geostrophic balance with the cross-shore pressure gradient force, the interface tilt also grows with time. Assuming steady $U$ and a linear time dependence for $V$, an approximate solution for $\zeta$ can be obtained (Csanady, 1973)

$\zeta_{\text {side }}(x, t)=\frac{L_{\mathrm{R}}}{R i} f t e^{-x / L_{\mathrm{R}}}$

The interface displacement at the coast is thus a linear function of $f t$ determined by $R i$ and $L_{\mathrm{R}}$.

Next consider the coast at the upwind end of the basin at $y=0$ and neglect all cross-axis gradients. After an initial spin-up period over which all accelerations $\partial U / \partial t \rightarrow 0$ and $\partial V / \partial t \rightarrow 0$, the surface wind stress balances a steady pressure gradient force near the coast and a steady along-shore Ekman flux far from the coast where $\partial \zeta / \partial y \rightarrow 0$. The interface displacement only grows large enough to accommodate this pressure gradient force balance. Assuming steady $U$ and zero $V$, an approximate solution for $\zeta$ can be obtained (Csanady, 1973)

$\zeta_{\text {end }}(y)=\frac{L_{\mathrm{R}}}{R i} e^{-y / L_{\mathrm{R}}}$

The interface displacement at the coast is once again determined by $R i$ and $L_{\mathrm{R}}$ but the solution is now steady with no continued growth. Comparing Equations 9 and 10, $\zeta_{\text {side }}$ clearly exceeds $\zeta_{\text {end }}$ for wind impulse durations longer than $t=1 / f$. Since $1 / f \approx 2.5 \mathrm{~h}$ at the SoG latitude while most upwelling-favorable wind events in the SoG persist from one to several days, $\zeta_{\text {side }}$ is unlikely to contribute significantly to upwelling.

While the linear time approximation used to obtain $\zeta_{\text {side }}$ becomes increasingly invalid as upwelling progresses, the interface displacement presumably continues to grow by some unknown function of $t$ until the coastal jet is balanced by bottom friction. This frictional adjustment period can be approximated by parameterizing the bottom friction according to a simple quadratic drag law $F_{y}=-C_{\mathrm{b}}\left(V / h_{2}\right)^{2}$ where $C_{\mathrm{b}}$ is the bottom drag coefficient. Substituting $F_{y}$ into Equation $8 \mathrm{~b}$ and solving for $V$ at the coast gives an $e$-folding time scale of $T_{F}=h_{2} / \sqrt{4 C_{b} \tau / \rho_{0}}$ (Csanady, 1974). For a typical drag coefficient of $C_{\mathrm{b}}=2 \times 10^{-3}$ 
and a nominal lower layer thickness of $h_{2}=100 \mathrm{~m}$, a wind stress of $\tau=0.2 \mathrm{~N} \mathrm{~m}^{-2}$ corresponding to a wind impulse of approximately $10 \mathrm{~m} \mathrm{~s}^{-1}$ produces a $T_{F}$ of approximately $1 \mathrm{~d}$. This estimated frictional adjustment period is smaller than the duration of a typical wind impulse in the SoG, however $T_{F}$ is still approximately an order of magnitude larger than the inertial time scale that governs $\zeta_{\text {end }}$.

\section{Case 2: Upwelling in a closed basin}

The infinite coast approximations ignore a fundamental mass conservation discontinuity at the upwind end of the basin where $x, y=0$. Along the side of the basin at $x=0$ there is a growing downwind coastal jet and along the end of the basin at $y=0$ there is a steady flux to the right of the wind in the positive $x$ direction. The resulting surface divergence at the corner causes the interface to lift upward and produce a cross-axis pressure gradient force. Similarly, at the downwind end of the basin at $x=L_{\mathrm{C}}$ and $y=L_{\mathrm{A}}$, there is a surface convergence and interface depression. As these cross-axis pressure gradients begin to oppose the cross-axis Ekman fluxes, downwind surface transport is no longer confined to within $L_{\mathrm{R}}$ of the ends and an along-axis interface tilt begins to emerge. These discontinuities exist even if $L_{\mathrm{C}} / L_{\mathrm{R}}>>1$.

If the cross-axis pressure gradients produced by the upwind corner divergence and downwind corner convergence propagate along the entire length of the basin, they will shut down all cross-axis Ekman fluxes. At this point, the along axis pressure gradient force will be the only term remaining to balance the wind stress once steady state is reached. Solving this reduced Equation $8 \mathrm{~b}$ for $\zeta$ between the end walls at $y=0, L_{\mathrm{A}}$ gives

$\zeta_{\text {closed }}(y)=\frac{L_{\mathrm{A}} / 2-y}{R i}$

Equation 11 describes the classic along-axis pycnocline setup observed in narrow lakes (Stevens and Lawrence, 1997). As

in Case 1, the interface displacement at the basin ends is determined by $R i$, however the length scale has now increased significantly from $L_{\mathrm{R}}$ to $L_{\mathrm{A}} / 2$. In the SoG, $L_{\mathrm{A}} / 2$ is approximately an order of magnitude larger than $L_{\mathrm{R}}$ which makes $\zeta_{\text {closed }}$ and $\zeta_{\text {side }}$ of similar order.

The along-axis interface displacement evolves as an internal seiche over a time scale $L_{\mathrm{A}} /(2 c)$, or one quarter of the fundamental seiche period, where $c=\sqrt{g^{\prime} h_{1} \delta_{h}}$ is the internal wave speed. However, the cross-shore pressure gradient at the upwind end of the basin driven by the corner divergence must first develop before the seiching begins, and this time scale is $L_{\mathrm{C}} / c$. The complete time scale is thus $T_{\text {setup }}=\left(L_{\mathrm{A}} / 2+L_{\mathrm{C}}\right) / c$. At the scale of the SoG, $T_{\text {setup }}$ can range from one to several days depending on $\Delta \rho$ and $h_{1}$, as they pertain to $c$. In the real SoG, $T_{\text {setup }}$ is likely at the long end of the estimated range because $c$ is likely slower than the shallow water estimate for reasons that will be discussed in Section 4.3.

Considering the scale of the SoG, the overall upwelling response to wind forcing could be described by both Equation 9 and Equation 11 during the respective early and later stages of the wind impulse. The transition from $\zeta_{\text {side }}$ to $\zeta_{\text {closed }}$ could theoretically occur as early as one day after the wind onset, or $T_{\text {setup }}$ could simply be too long to permit an observable transition at all. The PCA results suggest the latter, specifically that upwelling along the sides of the SoG is the dominant regime and any end effects are weakly significant at best. 
https://doi.org/10.5194/os-2021-21

Preprint. Discussion started: 1 April 2021

\subsection{Other geographic considerations}

There are two secondary features specifically in the nitrate EOF mode 3 spatial pattern that require additional consideration. The first feature is the significantly stronger nitrate anomaly in the northern SoG relative to the southern SoG along the eastern coastline (Figure 6d). In the theoretical context discussed in Section 4.1, this along-axis asymmetry could be interpreted as a partial influence of the narrow-basin regime summarized by Equation 11. However, this asymmetry is also overlapped by the along-axis stratification gradient produced by the Fraser River plume (Masson and Peña, 2009). The effect of this stratification gradient on upwelling strength is demonstrated to first order through the bulk Richardson number dependence identified in Equation 9. Since interface displacement is inversely proportional to the density difference across the interface $\Delta \rho$, we expect the weakly stratified northern SoG to experience stronger upwelling than the strongly stratified southern SoG, especially the Fraser plume region. In fact, we observe the surface nitrate anomaly in the EOF mode 3 spatial pattern to vanish nearly completely within approximately $50 \mathrm{~km}$ of the Fraser River mouth. For comparison, the western coastline nitrate upwelling EOF mode 1 does not exhibit such striking along-axis asymmetry (Figure 6b). In this case, the Fraser Plume is upwind while the downwind coastline is weakly-stratified due to the tidal injection that propagates south from Discovery Passage (Olson et al., 2020). Additionally, an along-axis interface tilt due the narrow-basin regime, if present, would now deepen the pycnocline along the downwind coastline and mitigate the effects of the weaker stratification in the north.

The second feature of the nitrate EOF mode 3 spatial pattern not fully explained by cross-axis upwelling is the surface nitrate anomaly throughout the western Discovery Islands (Figure 6d). While significantly weaker than the coastal upwelling anomaly, this island signal none-the-less warrants special consideration given the ecological importance of the Discovery Islands habitat. At the southern opening of these island channels, the nitrate anomaly appears to be a northern extension of the cross-axis upwelling signal. Inside the channels however, the nitrate anomaly is more uniform and less visibly associated with any particular shoreline. A previous analysis of surface nitrate using SalishSeaCast in this region found this wind-driven nitrate signal to contribute significantly to summer monthly standard deviations during 2016 and suggested the most likely source was advection of tidally-mixed nitrate from the northern passages (Olson et al., 2020). Given the high median surface nitrate that we observe in the northern passages of the Discovery Islands from our hindcast analysis (Figure 6a), we concur that southward advection of this persistent surface nitrate reservoir is a more accessible source of surface nitrate to the southern Discovery Islands than vertical mixing alone.

\subsection{Comparison to other study regions}

As mentioned in the introduction, the modes of upwelling discussed above in Section 4.1 have been clearly demonstrated in several well-studied systems across a range of dynamic scales. Specifically, cross-axis upwelling (Equation 9) dominates in dynamically wide basins like the Baltic Sea sub-basins (Bednorz et al., 2019) and in the North American Great Lakes (Plattner et al., 2006) while along-axis upwelling (Equation 11) dominates in dynamically narrow basins like the glacial reservoirs of British Columbia (Stevens and Lawrence, 1997). In the SoG where $L_{\mathrm{R}}$ approaches the basin width, the dynamic scale falls somewhere between these regimes. For context, the SoG is only narrower than Lake Ontario or the Gulf of Finland by 
https://doi.org/10.5194/os-2021-21

Preprint. Discussion started: 1 April 2021

approximately half. However, the SoG is also significantly more stratified due to the high salinity gradients and thus has a significantly larger $L_{\mathrm{R}}$. Ultimately, $L_{\mathrm{R}}$ in the SoG is never larger than half the basin width, and upwelling falls clearly into the cross-axis regime of a large basin according to the PCA results. The $L_{\mathrm{C}} / L_{\mathrm{R}}=1$ transition has been explored in fjords using an infinite channel approximation (Cushman-Roisin et al., 1994), but this exercise neglects the importance of the corner divergences that we propose in Case 2.

A striking contrast between the wind-driven pycnocline displacements in the SoG relative to the other systems discussed is the absence of basin-scale internal waves or seiches in our PCA results. Kelvin waves are an established wind response in large lakes including Lake Ontario (Csanady, 1977), Lake Geneva (Bouffard and Lemmin, 2013), Lake Iseo (Valerio et al., 2012) and Lake Tahoe (Roberts et al., 2021) while the presence of along-axis seiches in narrow lakes is well documented (Laval et al., 2008; Stevens and Lawrence, 1997). We attribute this absence of detectable wave responses to enhanced dissipation or damping as waves travel along the irregular coastline along the entire circumference of the SoG. Coastline irregularities have been demonstrated to significantly attenuate Kelvin wave amplitude and phase speed along continental margins (Mysak and Tang, 1974) and complete damping of along-axis seiches has been documented in the Nechako Reservoir (Imam et al., 2013). More conclusively, SalishSeaCast simulations using a smooth geometric bathymetry produce Kelvin wave-like rotating seiches excited by the cross-axis upwelling response that are absent when the realistic bathymetry is used (simulations not shown). In the context of Section 4.1 and Equation 11, the set-up time $T_{\text {setup }}$ ignores the effects of dissipation and damping on the internal wave speed and the real time scale is likely much longer. We thus suggest that the dominance of cross-axis upwelling observed in the PCA results is at least partially due to the interactions between seiches and complex topography.

\subsection{Ecosystem implications}

Our findings suggest that surface nitrate supply in the SoG during the productive season is primarily concentrated along the eastern and western coastlines and is stronger in the north relative to the south. While phytoplankton in the SoG are extensively sampled and studied, finding consistent patterns between observed phytoplankton biomass and these surface nitrate anomalies presents several challenges. One such challenge is that the along-axis phytoplankton distribution is already strikingly asymmetric due to the along-axis stratification gradient. Specifically, surface chlorophyll is generally higher in the strongly stratified southern SoG and generally lower in the weakly stratified northern SoG (Suchy et al., 2019; Masson and Peña, 2009). This surface chlorophyll gradient alone is opposite what we would expect given the enhanced northern nitrate upwelling revealed in this study. However the chlorophyll depth distribution is also wider in the northern SoG, with the highest depthintegrated biomass between Texada Island and Vancouver Island during the summer (Masson and Peña, 2009). More recently, an analysis of 5 years of sampled nitrate and chlorophyll profiles collected as part of the Pacific Salmon Foundation (PSF) Salish Sea Marine Survival Project revealed no significant along-axis spatial trends at the seasonal level (Pawlowicz et al., 2020). Given the comprehensive spatial and temporal coverage of this data set, this finding suggests that the northern-intensified upwelling that we observe does not significantly affect chlorophyll at the seasonal level. Rather, an event-based analysis of such a data set is likely necessary to provide additional detail into the along-axis chlorophyll response to wind driven nitrate upwelling. 
https://doi.org/10.5194/os-2021-21

Preprint. Discussion started: 1 April 2021

A second challenge is that nitrate upwelling events are episodic by nature and strongest near the shoreline, while nutrient and chlorophyll sampling are historically cruise-based and generally clustered toward the central axis of the SoG (Masson and Peña, 2009). Such a sampling program is effective for tracking seasonal cycles and interannual variability throughout the SoG, but may entirely miss systematic chlorophyll anomalies that appear during nitrate upwelling along the coast. More spatially comprehensive data sets like the PSF data set present an opportunity to resolve these chlorophyll anomalies, however no analysis of this data set with an emphasis on the nearshore areas of the northern SoG has been completed to date. Perhaps these upwelling-driven chlorophyll signals can be resolved in future sampling programs and modeling studies that specifically target these areas of enhanced nitrate upwelling.

Although nitrate is used as the primary upwelling tracer in this study, sub-pycnocline water is also associated with aragonite undersaturation and is thus potentially stressful for sensitive organisms such as shellfish. The two regions of particularly concentrated shellfish aquaculture activity identified in this study, Baynes Sound and the Discovery Islands, are both partially impacted by the wind-driven surface nitrate anomalies that we found in EOF modes 1 and 3. Baynes Sound in particular is centrally located along the Vancouver Island upwelling region (Figure 6b), and we reasonably expect this area to be impacted by sub-pycnocline water during southeasterly wind events. Conversely, the Discovery Islands are located outside of the main upwelling areas and we have stated previously that the nitrate anomalies that we observe in the EOF spatial fields in this region are primarily the result of surface advection. Continuous sampling at a shore station on Quadra Island maintained by the Hakai Institute has demonstrated rapid changes in temperature, salinity and aragonite saturation state immediately following strong northerly wind events (Evans et al., 2018). While the authors determined that wind energy input was sufficient to vertically mix the water column to the depth required to produce these changes, given the persistent southward surface velocities that accompany these wind events (Olson et al., 2020) we still argue that lateral advection likely plays a significant role in these water property changes.

\subsection{Limitations}

Based on the correlation between along-axis wind stress and the PC loadings time series, we have determined that the crossaxis surface nitrate gradients revealed by EOF modes 1 and 3 are produced by wind-driven upwelling. We have also identified two potential features that might explain the along-axis nitrate variability in EOF mode 1: an along-axis pycnocline tilt and an along-axis stratification gradient. However, identifying with certainty which of these features influences the along-axis upwelling gradient with any significance is beyond the capability of this analysis. Specifically, since in this contribution we have limited our data selection to surface wind, nitrate and temperature fields only, we cannot conclude whether the along-axis pycnocline tilt required to enhance the strength of upwelling in the north actually occurs. Furthermore, while we have related stratification and pycnocline depth to the strength of upwelling through the bulk Richardson number, we cannot quantitatively constrain this relationship using surface nitrate anomalies alone. Additionally, we have neglected other geographic features that have been suggested to influence upwelling strength such as cross-shore bottom slope (Choboter et al., 2011; Lentz and Chapman, 2004). Along-shore variations in bottom slope have been implicated in observations of spatially persistent upwelling hotspots in the Gulf of Finland (Delpeche-Ellmann et al., 2018). While explorations of pycnocline and nutricline depth changes 
https://doi.org/10.5194/os-2021-21

Preprint. Discussion started: 1 April 2021

are beyond the scope of the present study, they present a logical next step for furthering our understanding of wind-driven upwelling and the impacts on surface nutrient supply and carbonate chemistry in the SoG.

\section{Conclusions}

We analyzed 5 years of hourly, high resolution surface nitrate and temperature results from the SalishSeaCast biophysical coupled model along with hourly, high resolution surface wind forcing fields from the operational Canadian HRDPS weather model in order to better characterize the mechanism of wind driven surface nutrient delivery in the SoG. We found the primary HRDPS surface wind climatology to be oriented along the main axis of the SoG, with strong southeasterlies dominating in the winter and weaker northwesterlies dominating in the summer. This primary along-axis wind climatology produces periodic upwelling along the Vancouver Island coast during the spring and fall and along the British Columbia mainland coast during the summer. This upwelling response produces clear surface nitrate and temperature anomalies along these coasts, and these anomalies are largely absent near the ends of the SoG where tidal mixing dominates.

Using principal component analysis (PCA), we determined that the cross-axis upwelling patterns in surface nitrate account for a combined $\sim 30 \%$ of the variance across the 5 year record with the non-productive season, including winter, removed. By sharp contrast, nearly half of the surface temperature variance over the same period is dominated by a single mixing-heating pattern. The principal component loadings time series for these modes correlate consistently with time-averaged, along-axis wind stress calculated from the HRDPS wind record. For surface nitrate, a positive coastal nitrate anomaly band occurs to the right of the wind stress direction. For surface temperature, strong wind stress in either direction occurs with cool anomalies while weak wind stress occurs with warm anomalies. We attribute this contrast between surface nitrate and temperature to a deeper nitricline relative to the thermocline. Under northwesterly winds, the nitrate upwelling anomaly along the eastern coastline is significantly stronger in the northern SoG relative to the south.

The cross-axis upwelling response revealed by the PCA results is consistent with basins that are wider than the baroclinic Rossby deformation radius, and contrasts with the end-to-end pycnocline setup observed in narrow lakes. However, an alongaxis pycnocline tilt is theoretically possible in the SoG due to a divergence at the upwind corner of the basin. Such a tilt would be consistent with the along-axis nitrate anomaly gradient along the eastern shoreline, although the background alongaxis stratification gradient driven by the Fraser River could also explain this northern intensification of the surface nitrate anomaly. Regardless of the mechanism, this enchanced upwelling has implications for summer productivity in the northern SoG. Sampling biases toward the open water regions of the SoG may prevent the impacts of this nitrate upwelling source from being observed. Overall, the episodic nature of upwelling in the SoG may disrupt the background state of coastal habitats, whether from a nutrient perspective for bottom-up control of higher trophic levels or from a $\mathrm{pCO}_{2}$ perspective for sensitive shellfish aquaculture regions such as Baynes Sound and the Discovery Islands. 
https://doi.org/10.5194/os-2021-21

Preprint. Discussion started: 1 April 2021

(C) Author(s) 2021. CC BY 4.0 License.

(c) (1)

Code and data availability. All postprocessing and analysis scripts are available from the SalishSeaCast GitHub repository (https://github. com/SalishSeaCast/SoG_upwelling_EOF_paper). SalishSeaCast and HRDPS results are available from the SalishSeaCast ERDDAP server (https://salishsea.eos.ubc.ca/erddap/griddap/index.html). All observational data used in this study are available online from their respective organizations: Environment and Climate Change Canada (ECCC) meteorological station observations (https://climate.weather.gc.ca/ historical_data/search_historic_data_e.html), Fisheries and Oceans Canada (DFO) buoy observations (https://www.meds-sdmm.dfo-mpo.

570 gc.ca/isdm-gdsi/waves-vagues/data-donnees/index-eng.asp) and NASA MODIS Aqua images (https://oceancolor.gsfc.nasa.gov/cgi/browse. $\mathrm{pl}$ ?sen=amod). More information about SalishSeaCast can be found on the project web page (https://salishsea.eos.ubc.ca).

Author contributions. BMM performed the analyses and drafted the manuscript. SEA performed the hindcast simulations of SalishSeaCast. Both authors contributed equally to the development of the research concept and the manuscript beyond the initial draft. BMM is supervised by SEA.

575 Competing interests. The authors declare that no competing interests are present.

Acknowledgements. This work was funded by the Marine Environmental Observation, Prediction and Response (MEOPAR) Network of Canada (grant numbers 1.2, 7.2 and 37.1). Computational resources were provided by Compute Canada for hindcast runs (grant numbers FT520, RRG2648 and RRG2969) and Ocean Networks Canada for daily nowcast runs. The SalishSeaCast software environment was developed by Doug Latornell, and the SMELT ecosystem model was developed by Elise Olson. Additionally, Vy Do performed a significant amount of the preliminary analysis leading to this study as an undergraduate co-op student. 
https://doi.org/10.5194/os-2021-21

Preprint. Discussion started: 1 April 2021

\section{References}

Allen, S. E. and Wolfe, M. A.: Hindcast of the timing of the spring phytoplankton bloom in the Strait of Georgia, 1968-2010, Prog. Oceanogr., 115, 6-13, https://doi.org/10.1016/j.pocean.2013.05.026, 2013.

Bakri, T. and Jackson, P.: Statistical and synoptic analyses of offshore wind variations, Int. J. Climatol., 39, 3201-3217, https://doi.org/10.1002/joc.6012, 2019.

Bakri, T., Jackson, P., and Doherty, F.: A synoptic climatology of strong along-channel winds on the coast of British Columbia, Canada, Int. J. Climatol., 37, 2398-2412, https://doi.org/10.1002/joc.4853, 2017a.

Bakri, T., Jackson, P., and Doherty, F.: Along-channel winds in Howe Sound: climatological analysis and case studies, Atmos. Ocean, 55, 12-30, https://doi.org/10.1080/07055900.2016.1233094, 2017b.

Barth, J. A., Menge, B. A., Lubchenco, J., Chan, F., Bane, J. M., Kirincich, A. R., McManus, M. A., Nielsen, K. J., Pierce, S. D., and Washburn, L.: Delayed upwelling alters nearshore coastal ocean ecosystems in the northern California Current, PNAS, 104, 3719-3724, https://doi.org/10.1073/pnas.0700462104, 2007.

Bednorz, E., Półrolniczak, M., Czernecki, B., and Tomczyk, A. M.: Atmospheric forcing of coastal upwelling in the southern Baltic Sea basin, Atmosphere, 10, 327, https://doi.org/10.3390/atmos10060327, 2019.

Bouffard, D. and Lemmin, U.: Kelvin waves in Lake Geneva, J. Great Lakes Res., 39, 637-645, https://doi.org/10.1016/j.jglr.2013.09.005, 2013.

Bouffard, D., Kiefer, I., Wüest, A., Wunderle, S., and Odermatt, D.: Are surface temperature and chlorophyll in a large deep lake related? An analysis based on satellite observations in synergy with hydrodynamic modelling and in-situ data, Remote Sens. Environ., 209, 510-523, https://doi.org/10.1016/j.rse.2018.02.056, 2018.

Castelao, R. M. and Barth, J. A.: Coastal ocean response to summer upwelling favorable winds in a region of alongshore bottom topography variations off Oregon, J. Geophys. Res. Oceans, 110, C10S04, https://doi.org/10.1029/2004JC002409, 2005.

Chan, F., Barth, J. A., Blanchette, C. A., Byrne, R. H., Chavez, F., Cheriton, O., Feely, R. A., Friederich, G., Gaylord, B., Gouhier, T., Hacker, S., T. Hill, G. H., McManus, M. A., Menge, B. A., Nielsen, K. J., Russell, A., Sanford, E., Sevadjian, J., and Washburn, L.: Persistent spatial structuring of coastal ocean acidification in the California Current System, Nat. Sci. Rep., 7, 2526, https://doi.org/10.1038/s41598017-02777-y, 2017.

Chavez, F. P. and Messié, M.: A comparison of Eastern Boundary Upwelling Ecosystems, Prog. Oceanogr., 83, 80-96, https://doi.org/10.1016/j.pocean.2009.07.032, 2009.

Choboter, P. F., Duke, D., Horton, J. P., and Sinz, P.: Exact solutions of wind-driven coastal upwelling and downwelling over sloping topography, J. Phys. Oceanogr., 41, 1277-1296, https://doi.org/10.1175/2011JPO4527.1, 2011.

Collins, A. K., Allen, S. E., and Pawlowicz, R.: The role of wind in determining the timing of the spring bloom in the Strait of Georgia, Can. J. Fish. Aquat. Sci., 66, 1597-1616, https://doi.org/10.1139/F09-071, 2009.

Csanady, G. T.: Transverse internal seiches in large oblong lakes and marginal seas, J. Phys. Oceanogr., 3, 439-447, https://doi.org/10.1175/1520-0485(1973)003<0439:TISILO>2.0.CO;2, 1973.

Csanady, G. T.: Barotropic currents over the continental shelf, J. Phys. Oceanogr., 4, 357-371, https://doi.org/10.1175/15200485(1974)004<0357:BCOTCS>2.0.CO;2, 1974.

Csanady, G. T.: Intermittent 'full' upwelling in Lake Ontario, J. Geophys. Res., 82, 397-419, https://doi.org/10.1029/JC082i003p00397, 1977. 
https://doi.org/10.5194/os-2021-21

Preprint. Discussion started: 1 April 2021

Csanady, G. T.: Circulation in the Coastal Ocean, Springer, Dordrecht, Netherlands, https://doi.org/10.1007/978-94-017-1041-1, 1982.

Cushman-Roisin, B., Asplin, L., and Svendsen, H.: Upwelling in broad fjords, Cont. Shelf Res., 14, 1701-1721, https://doi.org/10.1016/02784343(94)90044-2, 1994.

Delpeche-Ellmann, N., Mingelaitè, T., and Soomere, T.: Examining Lagrangian surface transport during a coastal upwelling in the Gulf of Finland, Baltic Sea, J. Mar. Sys., 171, 21-30, https://doi.org/10.1016/j.jmarsys.2016.10.007, 2017.

Delpeche-Ellmann, N., Soomere, T., and Kudryavtseva, N.: The role of nearshore slope on cross-shore surface transport during a coastal upwelling event in Gulf of Finland, Baltic Sea, Estuar. Coast. Shelf Sci., 209, 123-135, https://doi.org/10.1016/j.ecss.2018.03.018, 2018.

Evans, W., Pocock, K., Hare, A., Weekes, C., Hales, B., Jackson, J., Gurney-Smith, H., Mathis, J. T., Alin, S. R., and Feely, R. A.: Marine $\mathrm{CO}_{2}$ patterns in the northern Salish Sea, Front. Mar. Sci., 5, 536, https://doi.org/10.3389/fmars.2018.00536, 2018.

Fatland, R., MacCready, P., and Oscar, N.: LiveOcean, in: Cloud Computing in Ocean and Atmospheric Sciences, edited by Vance, T. C., Merati, N., Yang, C., and Yuan, M., chap. 14, pp. 277-296, Academic Press, https://doi.org/10.1016/B978-0-12-803192-6.00014-1, 2016.

Flather, R. A.: A storm surge prediction model for the northern Bay of Bengal with application to the cyclone disaster in April 1991, J. Phys. Oceanogr., 24, 172-190, https://doi.org/10.1175/1520-0485(1994)024<0172:ASSPMF>2.0.CO;2, 1994.

Foreman, M. G. G., Walters, R. A., Henry, R. F., Keller, C. P., and Dolling, A. G.: A tidal model for eastern Juan de Fuca Strait and the southern Strait of Georgia, J. Geophys. Res. Oceans, 100, 721-740, https://doi.org/10.1029/94JC02721, 1995.

Foreman, M. G. G., Crawford, W. R., Cherniawsky, J. Y., Henry, R. F., and Tarbotton, M. R.: A high-resolution assimilating tidal model for the northeast Pacific Ocean, J. Geophys. Res. Oceans, 105, 28 629-28 651, https://doi.org/10.1029/1999JC000122, 2000.

Gurova, E., Lehmanna, A., and Ivanov, A.: Upwelling dynamics in the Baltic Sea studied by a combined SAR/infrared satellite data and circulation model analysis, Oceanologia, 55, 687-707, https://doi.org/10.5697/oc.55-3.687, 2013.

Haigh, R. and Taylor, F. J. R.: Mosaicism of microplankton communities in the northern Strait of Georgia, British Columbia, Mar. Biol., 110, 301-314, https://doi.org/10.1007/bf01313717, 1991.

Halverson, M. J. and Pawlowicz, R.: High-resolution observations of chlorophyll-a biomass from an instrumented ferry: influence of the Fraser River plume from 2003 to 2006, Cont. Shelf Res., 59, 52-64, https://doi.org/10.1016/j.csr.2013.04.010, 2013.

Harris, C. R., Millman, K. J., van der Walt, S. J., Gommers, R., Virtanen, P., Cournapeau, D., Wieser, E., Taylor, J., Berg, S., Smith, N. J., Kern, R., Picus, M., Hoyer, S., van Kerkwijk, M. H., Brett, M., Haldane, A., del Río, J. F., Wiebe, M., Peterson, P., Gérard-Marchant, P., Sheppard, K., Reddy, T., Weckesser, W., Abbasi, H., Gohlke, C., and Oliphant, T. E.: Array programming with NumPy, Nature, 585, 357-362, https://doi.org/10.1038/s41586-020-2649-2, 2020.

Hellerman, S. and Rosenstein, M.: Normal monthly wind stress over the world ocean with error estimates, J. Phys. Oceanogr., 13, 1093-1104, https://doi.org/10.1175/1520-0485(1983)013<1093:NMWSOT>2.0.CO;2, 1983.

Hollingsworth, A., Kållberg, P., Renner, V., and Burridge, D. M.: An internal symmetric computational instability, Q. J. R. Meteorolog. Soc., 109, 417-428, https://doi.org/10.1002/qj.49710946012, 1983.

Horst, P.: Factor Analysis of Data Matrices, Holt, Rinehart and Winston, New York, USA, 1965.

Hoyer, S. and Hamman, J.: xarray: N-D labeled arrays and datasets in Python, J. Open Res. Software, 5, https://doi.org/10.5334/jors.148, 2017.

Hunter, J. D.: Matplotlib: A 2D graphics environment, Comput. Sci. Eng., 9, 90-95, https://doi.org/10.1109/MCSE.2007.55, 2007.

Ianson, D., Allen, S. E., Moore-Maley, B. L., Johannessen, S. C., and Macdonald, R. W.: Vulnerability of a semienclosed estuarine sea to ocean acidification in contrast with hypoxia, Geophys. Res. Lett., 43, 5793-5801, https://doi.org/10.1002/2016GL068996, 2016. 
https://doi.org/10.5194/os-2021-21

Preprint. Discussion started: 1 April 2021

Imam, Y. E., Laval, B., Pieters, R., and Lawrence, G.: The strongly damped baroclinic response to wind in a multibasin reservoir, Limnol. Oceanogr., 58, 1243-1258, https://doi.org/10.4319/lo.2013.58.4.1243, 2013.

Jackson, P. L.: Surface winds during an intense outbreak of arctic air in southwestern British Columbia, Atmos. Ocean, 34, 285-311, https://doi.org/10.1080/07055900.1996.9649566, 1996.

Kaiser, H. F.: The varimax criterion for analytic rotation in factor analysis, Psychometrika, 23, 187-200, https://doi.org/10.1007/BF02289233, 1958.

Kämpf, J. and Chapman, P.: Upwelling Systems of the World, Springer, Cham, Switzerland, https://doi.org/10.1007/978-3-319-42524-5, 2016.

Khangaonkar, T., Nugraha, A., Xu, W., Long, W., Bianucci, L., Ahmed, A., Mohamedali, T., and Pelletier, G.: Analysis of hypoxia and sensitivity to nutrient pollution in Salish Sea, J. Geophys. Res. Oceans, 123, 4735-4761, https://doi.org/10.1029/2017JC013650, 2018.

Kluyver, T., Ragan-Kelley, B., Pérez, F., Granger, B., Bussonnier, M., Frederic, J., Kelley, K., Hamrick, J., Grout, J., Corlay, S., Ivanov, P., Avila, D., Abdalla, S., Willing, C., and Jupyter development team: Jupyter Notebooks - a publishing format for reproducible computational workflows, in: Positioning and Power in Academic Publishing: Players, Agents and Agendas, edited by Loizides, F. and Scmidt, B., pp. 87-90, IOS Press, Netherlands, https://doi.org/10.3233/978-1-61499-649-1-87, 2016.

Laval, B. E., Morrison, J., Potts, D. J., Carmack, E. C., Vagle, S., James, C., McLaughlin, F. A., and Foreman, M.: Wind-driven summertime upwelling in a fjord-type lake and its impact on downstream river conditions: Quesnel Lake and River, British Columbia, Canada, J. Great Lakes Res., 34, 189-203, https://doi.org/10.3394/0380-1330(2008)34[189:WSUIAF]2.0.CO;2, 2008.

Lehmann, A., Myrberg, K., and Höflich, K.: A statistical approach to coastal upwelling in the Baltic Sea based on the analysis of satellite data for 1990-2009, Oceanologia, 54, 369-393, https://doi.org/10.5697/oc.54-3.369, 2012.

Lentz, S. J. and Chapman, D. C.: The importance of nonlinear cross-shelf momentum flux during wind-driven coastal upwelling, J. Phys. Oceanogr., 34, 2444-2457, https://doi.org/10.1175/JPO2644.1, 2004.

Li, Y. and Li, M.: Wind-driven lateral circulation in a stratified estuary and its effects on the along-channel flow, J. Geophys. Res. Oceans, 111, C09 005, https://doi.org/10.1029/2011JC007829, 2012.

Lundesgaard, Ø., Powell, B., Merrifield, M., Hahn-Woernle, L., and Winsor, P.: Response of an antarctic peninsula fjord to summer katabatic wind events, J. Phys. Oceanogr., 49, 1485-1502, https://doi.org/10.1175/JPO-D-18-0119.1, 2019.

Mackas, D. L. and Harrison, P. J.: Nitrogenous nutrient sources and sinks in the Juan de Fuca Strait/Strait of Georgia/Puget Sound estuarine system: assessing the potential for eutrophication, Estuar. Coast. Shelf Sci., 44, 1-21, https://doi.org/10.1006/ecss.1996.0110, 1997.

Madec, G., Bourdallé-Badie, R., Bouttier, P.-A., Bricaud, C., Bruciaferri, D., Calvert, D., Chanut, J., Clementi, E., Coward, A., Delrosso, D., Ethé, C., Flavoni, S., Graham, T., Harle, J., Iovino, D., Lea, D., Lévy, C., Lovato, T., Martin, N., Masson, S., Mocavero, S., Paul, J., Rousset, C., Storkey, D., Storto, A., and Vancoppenolle, M.: NEMO ocean engine, Notes du Pôle de modélisation de l'Institut PierreSimon Laplace (IPSL): (27), https://doi.org/10.5281/zenodo.1472492, revision 8625 from SVN repository, 2017.

Marchesiello, P., McWilliams, J. C., and Shchepetkin, A.: Open boundary conditions for long-term integration of regional oceanic models, Ocean Model., 3, 1-20, https://doi.org/10.1016/S1463-5003(00)00013-5, 2001.

Masson, D.: Deep water renewal in the Strait of Georgia, Estuar. Coast. Shelf Sci., 54, 115-126, https://doi.org/10.1006/ecss.2001.0833, 2002.

690 Masson, D. and Peña, A.: Chlorophyll distribution in a temperate estuary: the Strait of Georgia and Juan de Fuca Strait, Estuar. Coast. Shelf Sci., 82, 19-28, https://doi.org/10.1016/j.ecss.2008.12.022, 2009. 
https://doi.org/10.5194/os-2021-21

Preprint. Discussion started: 1 April 2021

McKinney, W.: Data structures for statistical computing in Python, in: Proceedings of the 9th Python in Science Conference, edited by van der Walt, S. and Millman, J., pp. 56-61, https://doi.org/10.25080/Majora-92bf1922-00a, 2010.

Messié, M. and Chavez, F. P.: Seasonal regulation of primary production in eastern boundary upwelling systems, Prog. Oceanogr., 134, 1-18, https://doi.org/10.1016/j.pocean.2014.10.011, 2015.

Met Office: Cartopy: a cartographic Python library with a Matplotlib interface, Exeter, Devon, https://doi.org/10.5281/zenodo.3783894, 2010-2015.

Milbrandt, J. A., Bélair, S., Faucher, M., Vallée, M., Carrera, M. L., and Glazer, A.: The pan-Canadian high resolution (2.5 km) deterministic prediction system, Weather Forecast., 31, 1791-1816, https://doi.org/10.1175/WAF-D-16-0035.1, 2016.

Moore-Maley, B. L., Allen, S. E., and Ianson, D.: Locally driven interannual variability of near-surface $\mathrm{pH}$ and $\Omega_{A}$ in the Strait of Georgia, J., Geophys. Res. Oceans, 121, 1600-1625, https://doi.org/10.1002/2015JC011118, 2016.

Morrison, J., Foreman, M. G. G., and Masson, D.: A method for estimating monthly freshwater discharge affecting British Columbia coastal waters, Atmos. Ocean, 50, 1-21, https://doi.org/10.1080/07055900.2011.637667, 2012.

Mysak, L. A. and Tang, C. L.: Kelvin wave propagation along an irregular coastline, J. Fluid Mech., 64, 241-262, https://doi.org/10.1017/S0022112074002382, 1974.

Mziray, P., Kimirei, I. A., Staehr, P. A., Lugomela, C. V., Perry, W. L., Trolle, D., O'Reilly, C. M., and Mgana, H. F.: Seasonal patterns of thermal stratification and primary production in the northern parts of Lake Tanganyika, J. Great Lakes Res., 44, 1209-1220, https://doi.org/10.1016/j.jglr.2018.08.015, 2018.

Olson, E. M., Allen, S. E., Do, V., Dunphy, M., and Ianson, D.: Assessment of nutrient supply by a tidal jet in the northern Strait of Georgia based on a biogeochemical model, J. Geophys. Res. Oceans, 125, e2019JC015 766, https://doi.org/10.1029/2019JC015766, 2020.

Overland, J. E. and Walter Jr., B. A.: Gap winds in the Strait of Juan de Fuca, Mon. Weather Rev., 109, 2221-2233, https://doi.org/10.1175/1520-0493(1981)109<2221:GWITSO>2.0.CO;2, 1981

Parsons, T. R., Stronach, J., Borstad, G. A., Louttit, G., and Perry, R. I.: Biological fronts in the Strait of Georgia, British Columbia, and their relation to recent measurements of primary productivity, Mar. Ecol. Prog. Ser., 6, 237-242, https://doi.org/10.3354/meps006237, 1981.

Pawlowicz, R., Riche, O., and Halverson, M.: The circulation and residence time of the Strait of Georgia using a simple mixing-box approach, Atmos. Ocean, 45, 173-193, https://doi.org/10.3137/ao.450401, 2007.

Pawlowicz, R., Hannah, C., and Rosenberger, A.: Lagrangian observations of estuarine residence times, dispersion, and trapping in the Salish Sea, Estuar. Coast. Shelf Sci., 225, 106 246, https://doi.org/10.1016/j.ecss.2019.106246, 2019.

Pawlowicz, R., Suzuki, T., Chappell, R., Ta, A., and Esenkulova, S.: Atlas of oceanographic conditions in the Strait of Georgia (2015-2019) based on the Pacific Salmon Foundation's citizen science dataset, Can. Tech. Rep. Fish. Aquat. Sci., 3374, vii+116 p., 2020.

Peña, M. A., Masson, D., and Callendar, W.: Annual plankton dynamics in a coupled physical-biological model of the Strait of Georgia, British Columbia, Proj. Oceanogr., 146, 58-74, https://doi.org/10.1016/j.pocean.2016.06.002, 2016.

Plattner, S., Mason, D. M., Leshkevich, G. A., Schwab, D. J., and Rutherford, E. S.: Classifying and forecasting coastal upwellings in Lake Michigan using satellite derived temperature images and buoy data, J. Great Lakes Res., 32, 63-76, https://doi.org/10.3394/03801330(2006)32[63:CAFCUI]2.0.CO;2, 2006.

Preisendorfer, R. W.: Principal Component Analysis in Meteorology and Oceanography, Elsevier, Amsterdam, Netherlands, 1988.

Read, W. A.: The climatology and meteorology of windstorms that affect southwest British Columbia, Canada, and associated tree-related damage to the power distribution grid, Ph.D. thesis, University of British Columbia, https://doi.org/10.14288/1.0166485, 2015. 
https://doi.org/10.5194/os-2021-21

Preprint. Discussion started: 1 April 2021

Roberts, D. C., Egan, G. C., Forrest, A. L., Largier, J. L., Bombardelli, F. A., Laval, B. E., Monismith, S. G., and Schladow, G.: The setup and relaxation of spring upwelling in a deep, rotationally influenced lake, Limnol. Oceanogr., https://doi.org/10.1002/lno.11673, 2021.

Roubeyrie, L. and Celles, S.: Windrose: A Python Matplotlib, NumPy library to manage wind and pollution data, draw windrose, J. Open Source Softw., 3, 268, https://doi.org/10.21105/joss.00268, 2018.

Rowe, M. D., Anderson, E. J., Beletsky, D., Stow, C. A., Moegling, S. D., Chaffin, J. D., May, J. C., Collingsworth, P. D., Jabbari, A., and Ackerman, J. D.: Coastal upwelling influences hypoxia spatial patterns and nearshore dynamics in Lake Erie, J. Geophys. Res. Oceans, 124, 6154-6175, https://doi.org/10.1029/2019JC015192, 2019.

Schwab, D. J. and Beletsky, D.: Relative effects of wind stress curl, topography, and stratification on large-scale circulation in Lake Michigan, J. Geophys. Res. Oceans, 108, 3044, https://doi.org/10.1029/2001JC001066, 2003.

Shintani, T., de la Fuente, A., Niño, Y., and Imberger, J.: Generalizations of the Wedderburn number: Parameterizing upwelling in stratified lakes, Limnol. Oceanogr,, 55, 1377-1389, https://doi.org/10.4319/lo.2010.55.3.1377, 2010.

Silvestrova, K., Myslenkov, S., and Zatsepin, A.: Variability of wind-driven coastal upwelling in the north-eastern Black Sea in 1979-2016 according to NCEP/CFSR data, in: Meteorology and Climatology of the Mediterranean and Black Seas, edited by Vilibić, I., Horvath, K., and Palau, J. L., Pageoph Topical Volumes, pp. 287-295, Birkhäuser, Cham, https://doi.org/10.1007/978-3-030-11958-4_17, 2019.

Soontiens, N. and Allen, S. E.: Modelling sensitivities to mixing and advection in a sill-basin estuarine system, Ocean Model., 112, 17-32, https://doi.org/10.1016/j.ocemod.2017.02.008, 2017.

Soontiens, N., Allen, S. E., Latornell, D., Souëf, K. L., Machuca, I., Paquin, J.-P., Lu, Y., Thompson, K., and Korabel, V.: Storm surges in the Strait of Georgia simulated with a regional model, Atmos. Ocean, 54, 121, https://doi.org/10.1080/07055900.2015.1108899, 2016.

Spall, M. A., Jackson, R. H., and Straneo, F.: Katabatic wind-driven exchange in fjords, J. Geophys. Res. Oceans, 122, 8246-8262, https://doi.org/10.1002/2017JC013026, 2017.

Spigel, R. H. and Imberger, J.: The classification of mixed-layer dynamics of lakes of small to medium size, J. Phys. Oceanogr., 10, 1104-1121, https://doi.org/10.1175/1520-0485(1980)010<1104:TCOMLD>2.0.CO;2, 1980.

Stahl, K., Moore, R. D., and Mckendry, I. G.: The role of synoptic-scale circulation in the linkage between large-scale ocean-atmosphere indices and winter surface climate in British Columbia, Canada, Int. J. Climatol., 26, 541-560, https://doi.org/10.1002/joc.1268, 2006.

Stevens, C. L. and Lawrence, G. A.: Estimation of wind-forced internal seiche amplitudes in lakes and reservoirs, with data from British Columbia, Canada, Aquat. Sci., 59, 115-134, https://doi.org/10.1007/BF02523176, 1997.

Suchy, K. D., Le Baron, N., Hilborn, A., Perry, R. I., and Costa, M.: Influence of environmental drivers on spatio-temporal dynamics of satellite-derived chlorophyll $a$ in the Strait of Georgia, Prog. Oceanogr., 176, 102 134, https://doi.org/10.1016/j.pocean.2019.102134, 2019.

Sutton, J. N., Johannessen, S. C., and Macdonald, R. W.: A nitrogen budget for the Strait of Georgia, British Columbia, with emphasis on particulate nitrogen and dissolved inorganic nitrogen, Biogeosci., 10, 7179-7194, https://doi.org/10.5194/bg-10-7179-2013, 2013.

Thompson, H. D., Déry, S. J., Jackson, P. L., and Laval, B. E.: A synoptic climatology of potential seiche-inducing winds in a large intermontane lake: Quesnel Lake, British Columbia, Canada, Int. J. Climatol., 40, 5973-5986, https://doi.org/10.1002/joc.6560, 2020.

Thomson, R. E. and Huggett, W. S.: M2 baroclinic tides in Johnstone Strait, British Columbia, J. Phys. Oceanogr., 10, 1509-1539, https://doi.org/10.1175/1520-0485(1980)010<1509:MBTIJS>2.0.CO;2, 1980.

Thomson, R. E., Beamish, R. J., Beacham, T. D., Trudel, M., Whitfield, P. H., and Hourston, R. A. S.: Anomalous ocean conditions may explain the recent extreme variability in Fraser River sockeye salmon production, Mar. Coast. Fish., 4, 415-437, https://doi.org/10.1080/19425120.2012.675985, 2012. 
https://doi.org/10.5194/os-2021-21

Preprint. Discussion started: 1 April 2021

(c) Author(s) 2021. CC BY 4.0 License.

(c) (i)

Thomson, R. E., Kulikov, E. A., Spear, D. J., Johannessen, S. C., and Wills, W. P.: A role for gravity currents in cross-sill estuarine exchange and subsurface inflow to the southern Strait of Georgia, J. Geophys. Res. Oceans, 125, e2019JC015374, https://doi.org/10.1029/2019JC015374, 2020.

Troitskaya, E., Blinov, V., Ivanov, V., Zhdanov, A., Gnatovsky, R., Sutyrina, E., and Shimaraev, M.: Cyclonic circulation and upwelling in Lake Baikal, Aquat. Sci., 77, 171-182, https://doi.org/10.1007/s00027-014-0361-8, 2015.

Unidata: Network Common Data Form (netCDF) version 4.5.4 [software], UCAR/Unidata, Boulder, CO, https://doi.org/10.5065/D6H70CW6, 2019.

Valerio, G., Pilotti, M., Marti, C. L., and Imberger, J.: The structure of basin-scale internal waves in a stratified lake in response to lake bathymetry and wind spatial and temporal distribution: Lake Iseo, Italy, Limnol. Oceanogr., 57, 772-786, https://doi.org/10.4319/lo.2012.57.3.0772, 2012.

Wasmund, N., Nausch, G., and Voss, M.: Upwelling events may cause cyanobacteria blooms in the Baltic Sea, J. Mar. Sys., 90, 67-76, https://doi.org/10.1016/j.jmarsys.2011.09.001, 2012.

Wasser, S. K., Lundin, J. I., Ayres, K., Seely, E., Giles, D., Balcomb, K., Hempelmann, J., Parsons, K., and Booth, R.: Population growth is limited by nutritional impacts on pregnancy success in endangered Southern Resident killer whales (Orcinus orca), PLoS One, 12, e0179 824, https://doi.org/10.1371/journal.pone.0179824, 2017.

Wessel, P. and Smith, W. H. F.: A global, self-consistent, hierarchical, high-resolution shoreline database, J. Geophys. Res. Solid Earth, 101, 8741-8743, https://doi.org/10.1029/96JB00104, 1996.

Yin, K., Goldblatt, R. H., Harrison, P. J., John, M. A. S., Clifford, P. J., and Beamish, R. J.: Importance of wind and river discharge in influencing nutrient dynamics and phytoplankton production in summer in the central Strait of Georgia, Mar. Ecol. Prog. Ser., 161, 173183, https://doi.org/10.3354/meps161173, 1997.

Zhurbas, V., Laanemets, J., and Vahtera, E.: Modeling of the mesoscale structure of coupled upwelling/downwelling events and the related input of nutrients to the upper mixed layer in the Gulf of Finland, Baltic Sea, J. Geophys. Res. Oceans, 133, C05004, https://doi.org/10.1029/2007JC004280, 2008. 